\title{
المخالفات العقدية في زمن الأوبئة (كورونا أنموذجًاً)
}

$$
\text { وفاء الخميس }
$$

جامعة الملك سعود- المملكة العربية السعودية walkhamees@ksu.edu.sa 


\title{
المخالفات العقدية في زمن الأوبئة (كورونا أنموذجًا)
}

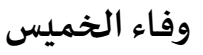 \\ جامعة الملك سعود- المملكة العربية السعودية
}

walkhamees@ksu.edu.sa

DOI: https://doi.org/10.31559/SIS2020.5.2.3

الملتخص:

نظرًا لما اجتاح العالم خلال العامين (المنصرم والحالي) من وباء عام أقفلت بسببه مناشط الناس؛ فمن المهم للإنسان دراسة هذا الأمر، وأثره في نفوس الناس، حيث ظهر في الناس بعض المخالفات التي تمس عقيدة المسلم وإيمانه؛ لذا آثرت دراسة تلك الك المخالفات دراسـة علمياة تحمل عنوان: "المخالفات العقدية في زمن الأوبئة- كورونا أنموذجًا" مشاركة مني في العدد الخاص للمجلة الدولية للدراسات الإسلامية المتخصصة. هدفت الدراسة إلى معرفة الفرق بين المرض والوباء والجائحةد، التعريف بالمنههج الشرعي في

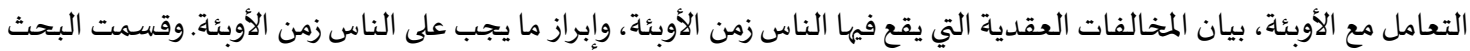
إلى مقدمة وتمهيد ومبحثين وخاتمة.

الكلمات المفتاحية: مخالفة، عقيدة، إيمان، قَدَر، توكل، تشـاؤم، يأس، أمراض، أوبئة، كورونا.

الحمد الله رب العالمين والصلاة والسلام على أشرف الأنبياء والمرسلين نبينا محمد صلى الله عليه وعلى آله وصحبه أجمعين. وبعد:

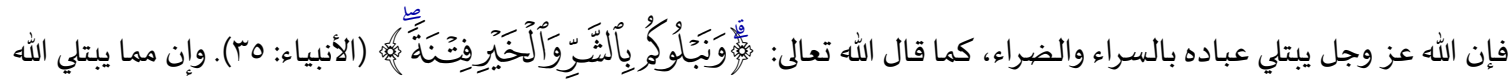
تعالى باه عباده: الأمراض التي قد تَعْرِض لأفراد الناس، وقد تجتاح قُطرًا أو إقليمًا فتخلف خسـائر كبيرة في الناس والاقتصاد. ولا شك مُك

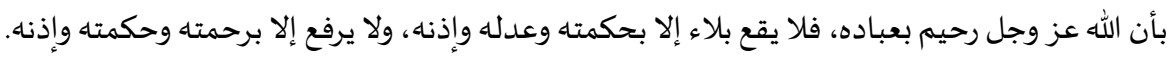

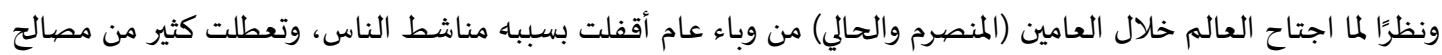

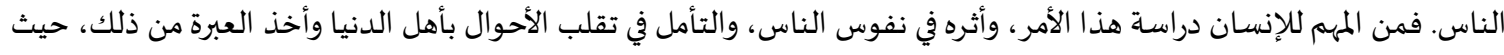
ظهر في الناس بعض المخالفات التي تمس عقيدة المسلم وإيمانه؛ لذا آثرت دراسة تلك المخالفات دراسة علمية (وإن كانت مختصرة) في

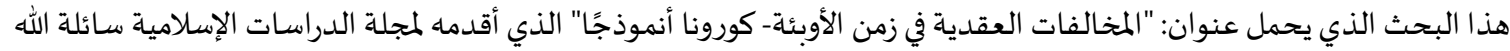
عز وجل الإخلاص والتوفيق والسـد اد.

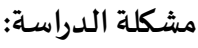

لما كان من سنة الله عز وجل اختلاف الناس في أحوالهم وأقوالهم وأعمالهم ولا سيما عند وقوع الأمراض والجوائح؛ كان لا بد من معرفة ما قد يخالف فيه الناس عقيدة الإسلام أثناء وقوع تلك الجوائح، ودراستها، لتوعية الناس بأثرها السيء على عقيدة المسلم وعبادته، والدلالة على الطريقة الصحيحة السليمة التي يحافظ بها المسلم على عقيدته من الزلل والخطأ. 


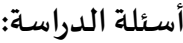

1. ما الفرق بين المرض والوباء والجائحة؟ المبه

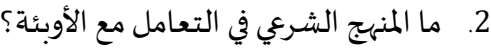

3. ما المخالفات العقدية التي يقع فيها الناس زمن الأوبئة ؟

4. ما الواجب على الناس (بمختلف فئاتهم) زمن الأوبئة؛

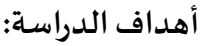

1

2. التعريف بالمنهج الشرعي في التعامل مع الأوبئة.

3. بيان المخالفات العقدية التي يقع فيها الناس زمن الأوبئة.

4. إبراز ما يجب على الناس زمن الأوبئة.

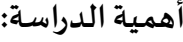

ترتبط أهمية الدراسة بأهمية دين المسلم وايمانه، الذي هو أصل قبول العمل، حيث يساهم في توعية الناس بأهمية العقيدة، وصيانة التوحيد عن كل ما يدنّسـاء. وإلقاء الضيوء على بعض المخالفات التي يمكن أن يقع فهها الناس دون انتباه لخطورة بعض الممارسات

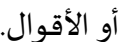

منهج الدراسـة وطريقتها:

يعتمد البحث المنهج الوصفي التحليلي والنقدي، أما خطوات العمل فهي على النحو التالي: 1. عزو الآيات القرآنية في متن البحث واستخدام خطوط المصحف العثماني.

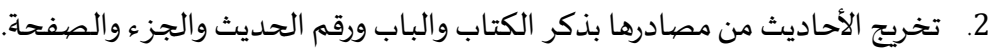

3. توثيق المصادر والمراجع حسب ضوابط المجلة.

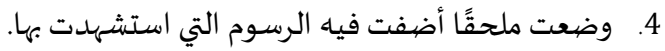

5. رغبة في الاختصار: تركت الترجمة لجميع الأعلام الوارد ذكرهم في متن البحث، واكتفيت بتاريخ وفياتهم، لكني لم أنقل تاريخ وفيات

الصحابة لاشتهارهم مثيّة وإطباق الأمة على معرفتهم.

6. اعتمدت في توثيق المخالفات (في هذا الوباء) على وسائل الإعلام والمواقع الإلكترونية.

7. ويتكون هذا البحث من مقدمة، وتمهيد، ومبحثين وخاتمة.

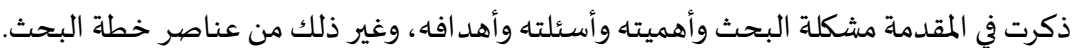

وفي التمهيد عرَّفت بأهم المصطلحات موضهوع الدراسـة. وفي المبحث الأول تناولت بعض المسائل العقدية المرتبطة بهذا الوباء موضوع المراء. أما المبحث الثاني فكان عن المخالفات العقدية التي يقع فيها الناس زمان الأوبئة. وفي الخاتمة ذكرت أهم النتائج المتوصل لها، ومن ثم أهم التوصيات. واختتمت البحث بفهرسين، واحد للمراجع والمصادر، وواحد للموضوعات، فمع الاختصار لا يحتاج الباحث إلى فهارس للآيات أو

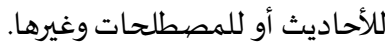
ولا يخلو أي عمل من صعوبات في طريق صاحباء، وأهم الصعوبات التي واجهتني أثناء إعداد هذا البحث: قلة المصادر والمراجع

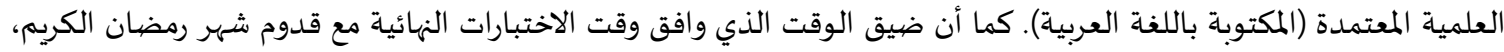
والحمد لله على عونه وتيسيره، وأسأله السد اد والتوفيق.

ولا يفوتني في الختام: شكر المجلة الدولية للدراسات الإسلامية المتخصصية على تمكينهم لي لنشر هذا البحث، وأثني بالشكر

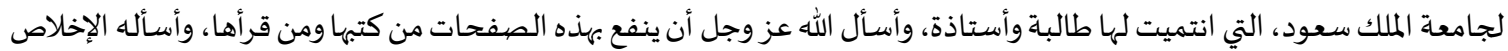
في القول والعمل، والحمد لله رب العالمين. 


\section{تمهييد: التعريف بأهم مصطلحات الدراسة}

يدور البحث على المخالفات العقدية زمن الأوبئة، فما الوباء وما الفرق بينه وبين المرض الجائحة؟ وما هو فيروس كورونا؟ هذا ما

تجيب عليه الفقرات التالية:

تعريف المرض:

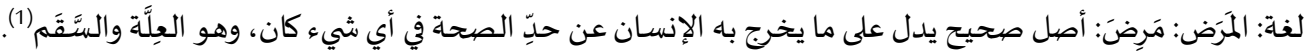
اصطلاحًا: اعتلال الجسم أو العقل، وتصيب الأمراض أي جزء في الجسم، وتؤثر فيه، ويمكن أن يكون عارضًا خفيفًا كالتهاب الحلق، أو خطيرًا مثل النوبة القلبية (2).

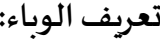

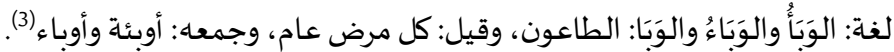

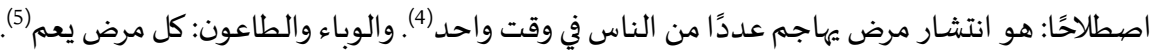
تعريف الجائحة: لغذة: جَوَحَ أصل واحد، وهو الاستئصيال من الاجتياح، ومنها اشتقت الجائحة. وقيل هو الهلاك. وأصل الجائحة: السنـة الشـديدة تجتاح الأموال(6). تعربف الفيروس:

الفيروس لفظ لاتيني بمعنى السُّم. وهو كائن مجهري يعيش داخل خلية كائن حي آخر. وتسبب الفيروسات العديد من الأمراض(7). أما كورونا: فهو عبارة عن فيروس من فصيلة فيروسات كورونا (أو الفيروسات التاجية)) ، أعراضيه تشمل الحمى والسعال وضيق التنفس، وقد تتطور

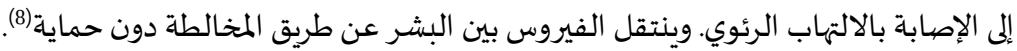
الفرق بين المرض والوباء والجائحة: المرض: لفظ يشمل الأمراض المعدية وغير المعدية. أما إذا انتقل المرض من إنساء وإن لآخر ، سمي مرضًا سـاريًا، فإذا اكتسب المرض قدرة

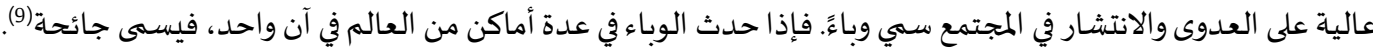
ويمكن بعد هذا العرض ملاحظة شيء من الاختلاف بين المعنى اللغوي، وما اصطلحت عليه الهيئات الصحية العالمياة، وبالتالي: وزارات الصحة في عالمنا العربي.

\section{المبحث الأول: المسـائل الاعتقادية المتعلقة بوباء كورونا} منذ أن وقع البلاء في هذا العالم، وإلى اليوم والمتأمل يرى أمورًا كثيرة قد يغفل عنها كثير من الناس، منها ما يتعلق بالجوانب الاعتقادية، ومنها ما يتعلق بالجوانب الجسدية، والنفسية. لكن موضوع البحث هنا هو الاعتقاد، ويمكن التعريج على بعض المسائل الاعتقادية من خلال المطالب التالية: المطلب الأول: ظهور أسماء الله تعالى وصفاته

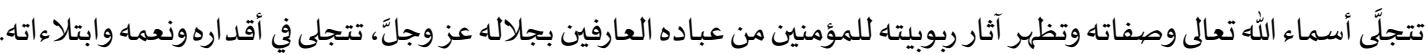
قال ابن القيم رحماه الله تعالى (ت: 751هـ): "الحمد الله الذي ظهر لأوليائه بنعوت جلاله، وأنار قلوبهم بمشاهدة صهفات كماله، وتعرَّف إلههم بما أسداه إلههم من إنعامه وإفضاله، فعلموا أنه الواحد الأحد، الفرد الصمد، الذي لا شريك له في ذاته ولا في صفاته ولا في أفعاله،

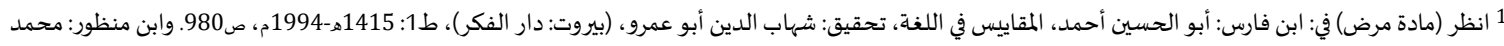

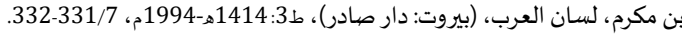

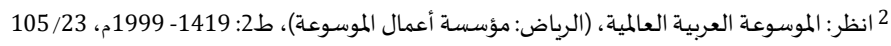

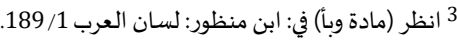

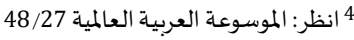

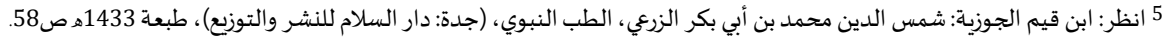

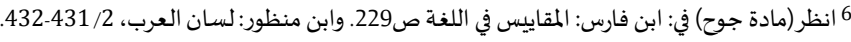

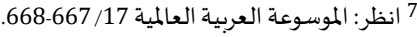


بل هو كما وصف به نفساه وفوق ما يصفه باه أحد من خلقه في إكثاره وإقلاله، لا يحصي أحد ثناءً عليه، بل هو كما أثنى على نفساء"(10).

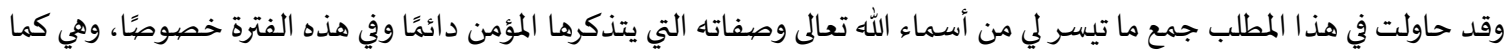

القديروالقادروالمقتدروالقوي:

وهذه الأسماء تجعل المؤمن خاضعًا لله عز وجل، منكسرًا بين يدياء يخشى العقوبة كما يرجو الرحمة، فإن الله عز وجل لا معجز

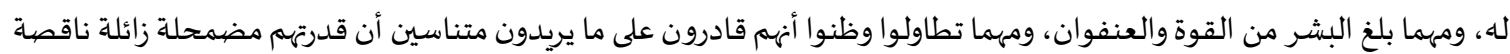

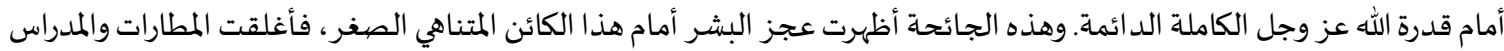

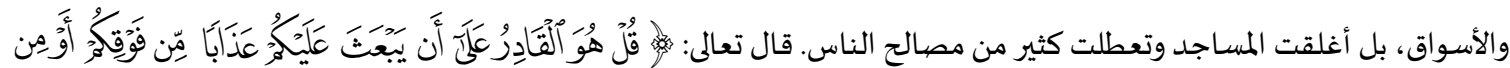

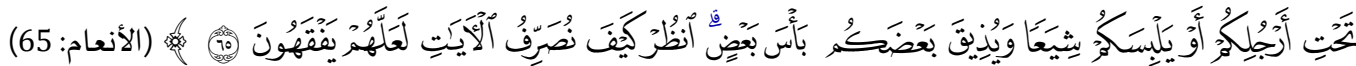

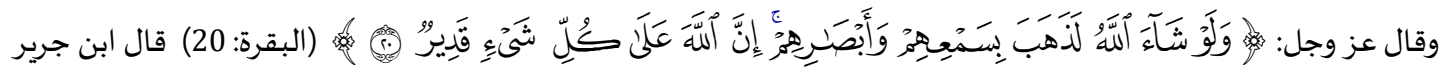
رحمه الله (ت: 310ه): "إنما وصف الله نفسه -جلَّ ذكره- بالقدرة على كل شيء في هذا الموضع؛ لأنه حذَّر المنافقين بأسه وسطوته،

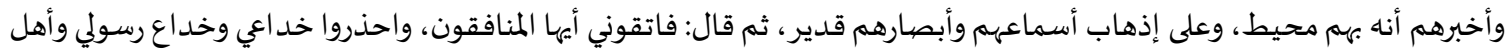
الإيمان بي، لا أحل بكم نقمتي، فإني على ذلك وعلى وعلى غيره من الأشياء قدير "(11).

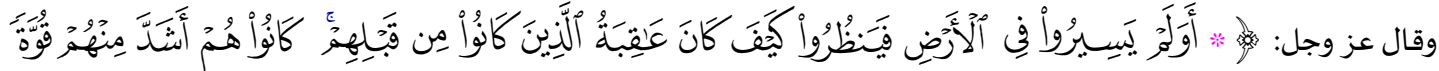

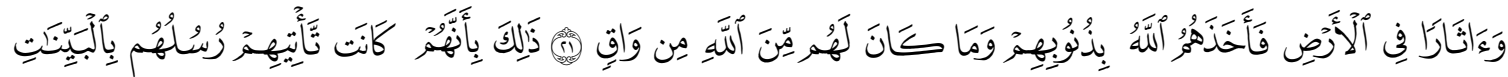

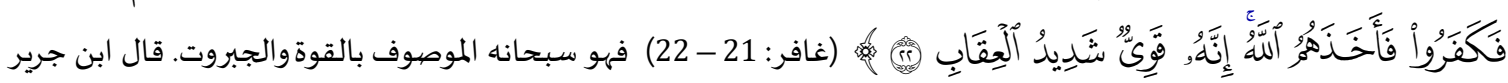
رحماء الله (ت: 310هـ): "إن الله ذو قوة لا يقهره شيء، ولا يغلباء، ولا يعجزه شيء أراده، شديد عقابه" (12).

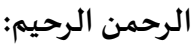
فالله سبحانها رحمن رحيم لا يبتلي إلا ليرحم، فبرحمته يعطي عباده الصابرين أجرهم بغير حساب، وتتجلى رحمة الله تعالى بخلقه

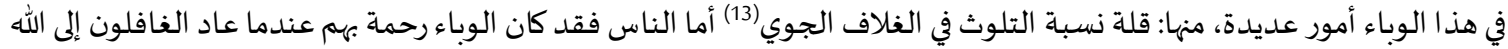
تعالى يستغفرونه ويسألونه، وكان في الوباء رحمة بالناس حيث عاد الناس إلى بيوتهم، وتغيرت إيجابًا نظرة كثير من الناس حيث بـاء بات رهات

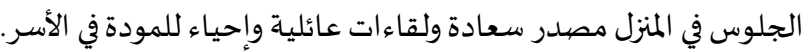
والرحمن والرحيم "اسمان دالّان على أنه ذو الرحمة الواسعة العظيمة التي وسعت كل شيء، وعمَّت كل حي، وكتبها الله للمتقين

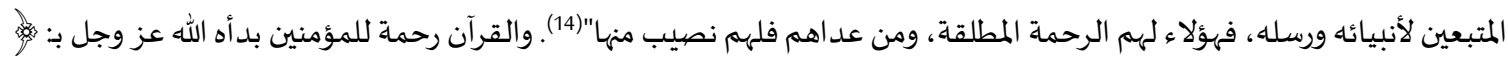

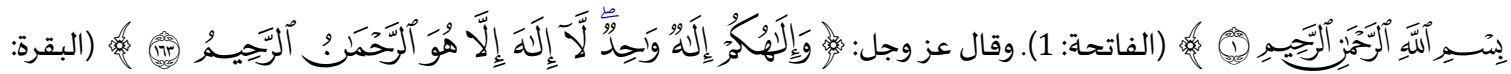

العليم والعالم: (10) ظهر في هذا الوباء مبلغ قصور علم الناس كافة، رغم ما حصيّلوه من علوم ومعارف، ورغم تقدّم العلوم كافة، فما زالت اللقاحات والأدوية محاولات بشرية للسيطرة عليه. ولا أحد يعلم متى يصاب ومتى يتخلص جسممه من هذا الفيروس، ولا أحد يعلم متى تعود حياتنا

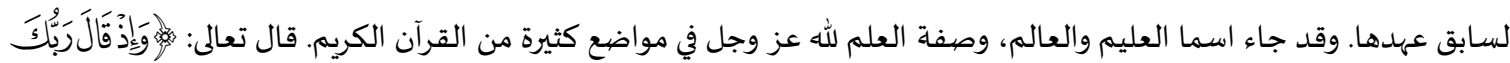

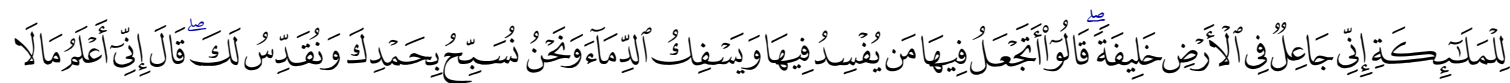

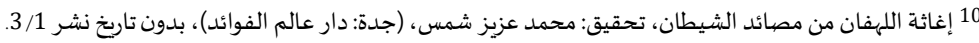

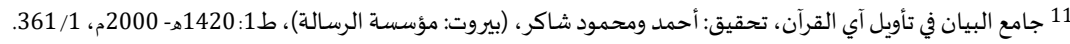
372/21 جامع البيان 12 البيان https://www.bbc.com/arabic/vert-fut-52477299:وhttps://www.bbc.com/arabic/vert-fut-52151140 13 انظر مثلاً النيان 14 السعدي: عبد الرحمن بن ناصر، تيسير الكريم الرحمن في تفسير كلام المنان، تحقيق: د. عبد الرحمن بن معلا اللويحق، (بيروت: مؤسسة الرسالة)، ط1: 1421هــ 2000م، 


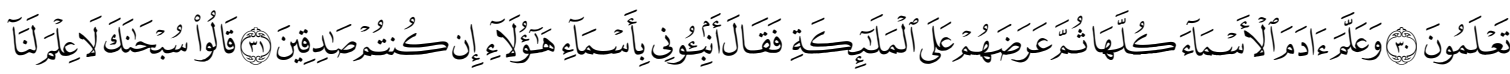

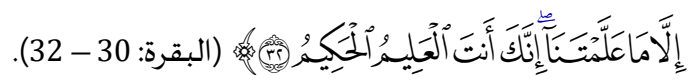

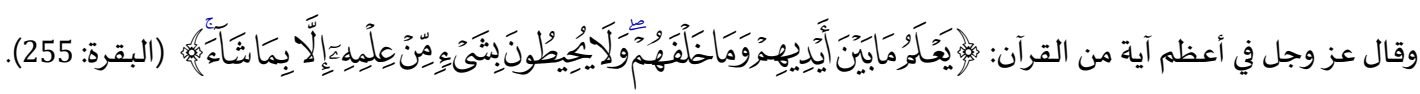

$$
\text { المطلب الثاني: العبادات القلبية (أعمال القلوب) }
$$

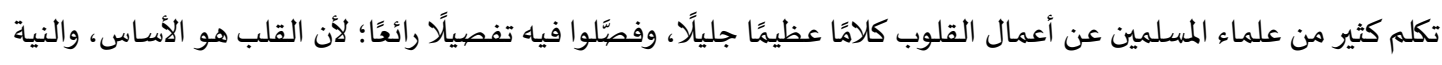

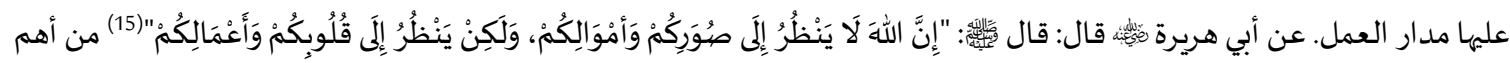

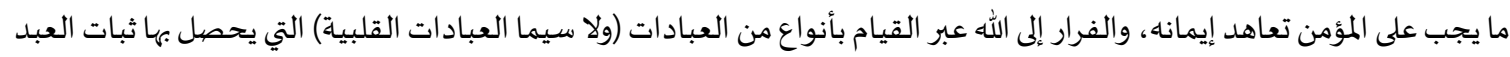

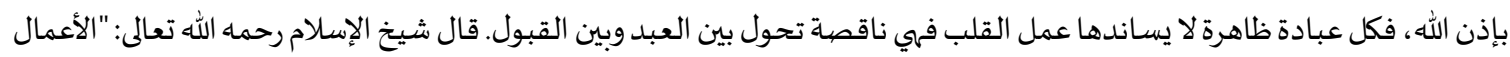

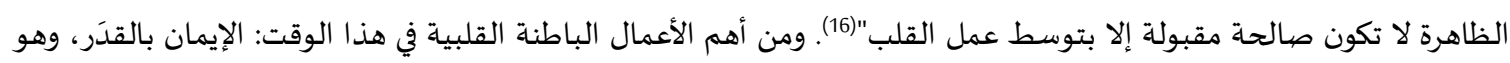

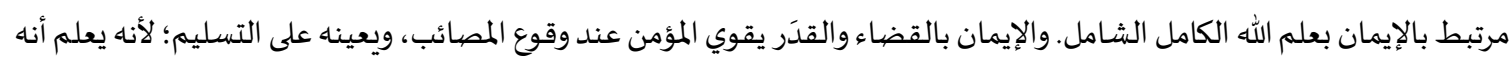

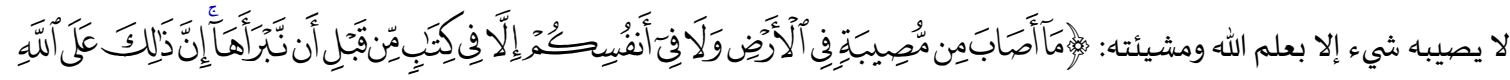

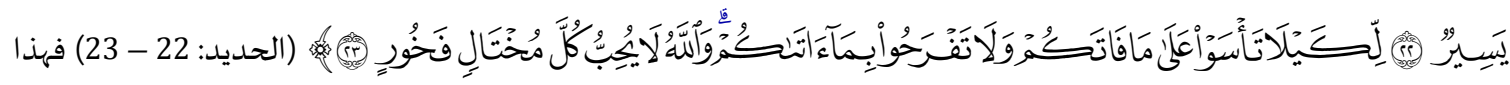

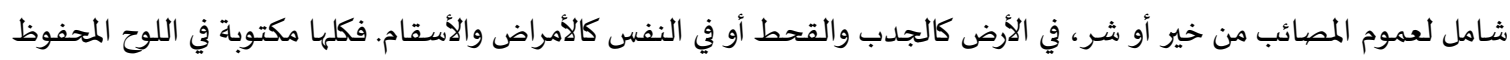

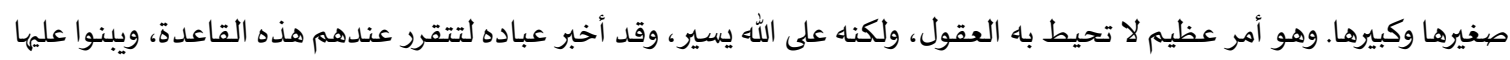

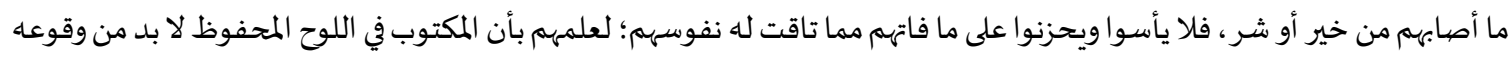

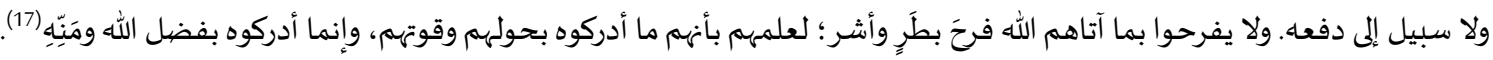

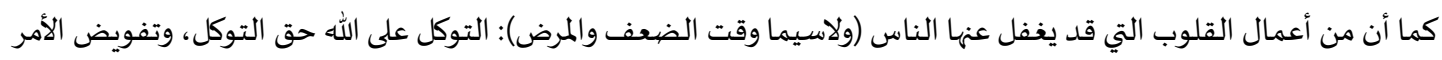

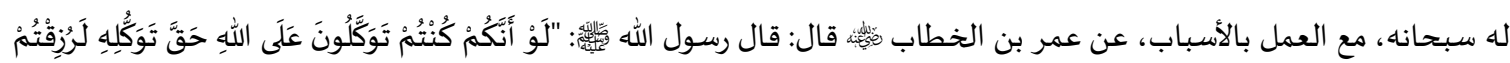

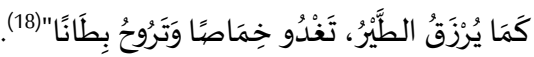

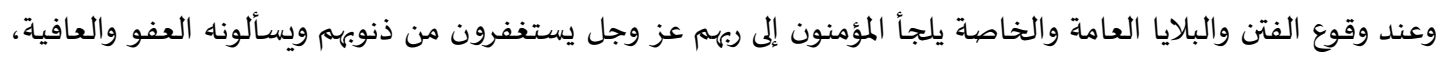

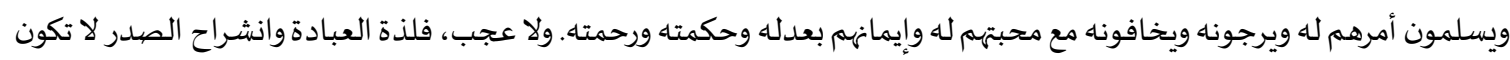

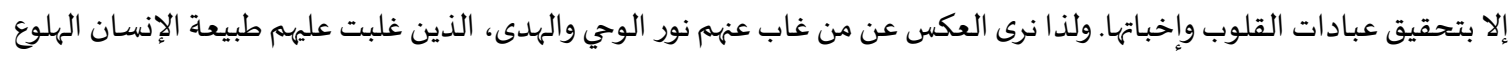

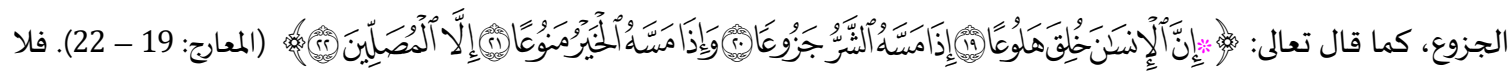

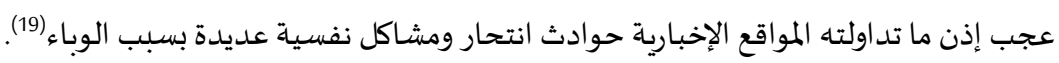

\section{المبحث الثاني: المخالفات العقدية في زمن الأوبئة}

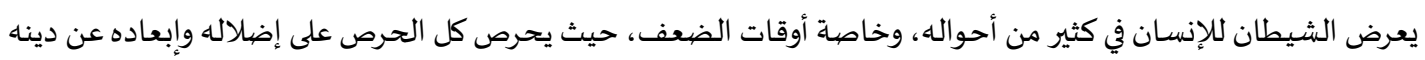
ما استطاع. وهاهنا رصد لأهم المخالفات العقدية التي يقع في الناس حال الأوبئة أعرضها في المطالب التالية:

المطلب الأول: مخالفات متعلقة بالإيمان بالقَدَروالتوكل

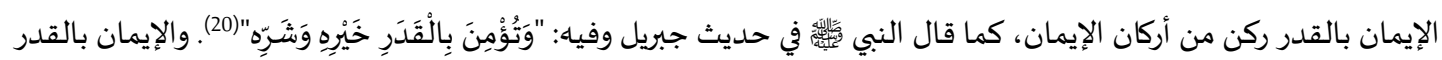

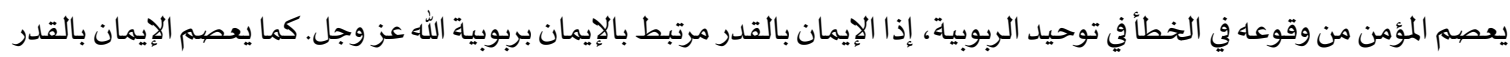

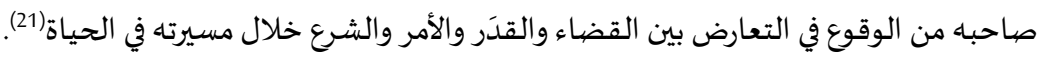

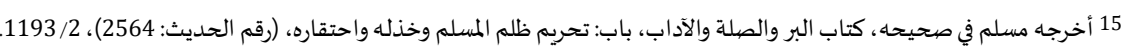

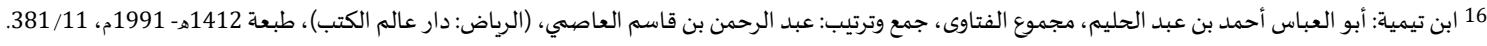

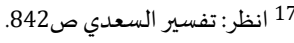

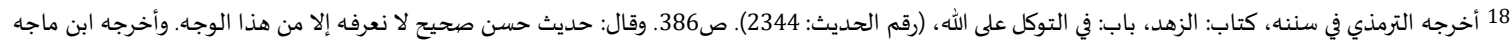

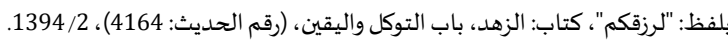
و https://arabic.cnn.com/health/article/2020/03/25/italy-coronavirus-doctors-death-toll-24-nurse-commits-suicide 19 https://arabic.cnn.com/health/article/2020/03/25/italy-coronavirus-doctors-death-toll-24-nurse-commits-suicide

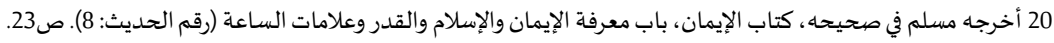

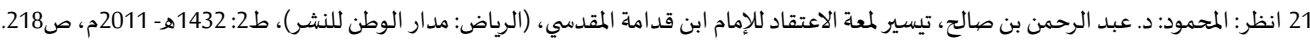




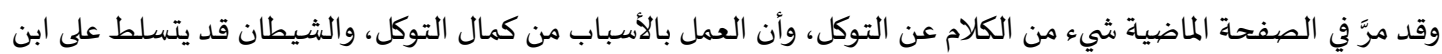

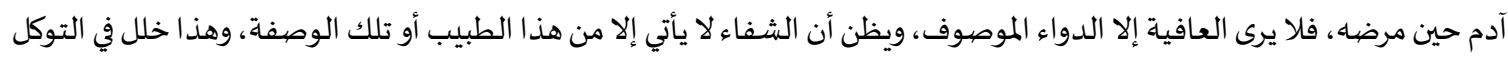

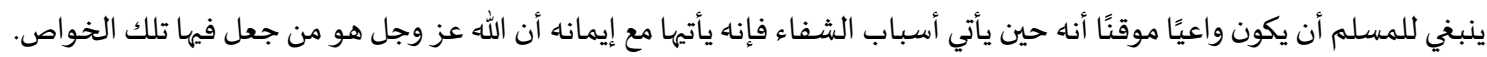

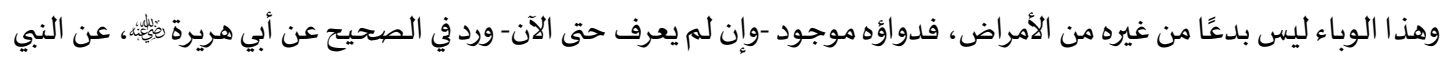

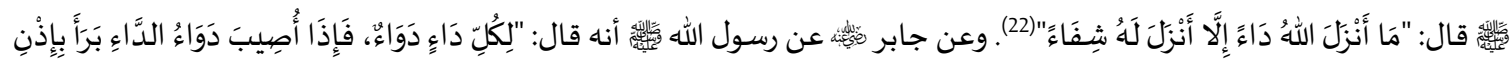

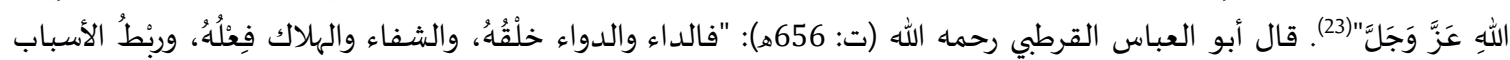

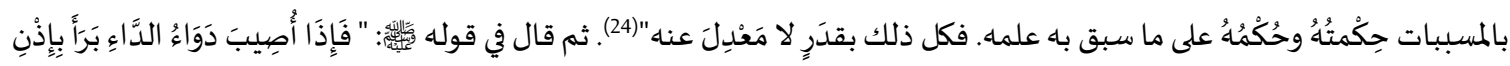

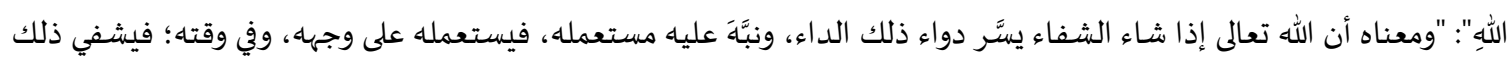

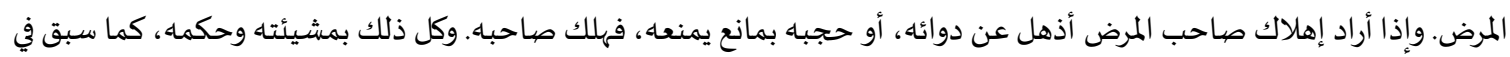

وقد ظهر لي من تتبع بعض المواقع الإخبارية ووسائل التواصل الاجتماعي مما يمكن اعتباره خطاً متعلقًا بالاعتقاد في باب القدر

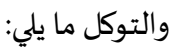

\section{الجزع عند وقوع المرض (خاصة بعد النتشاره):}

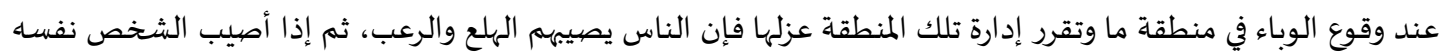

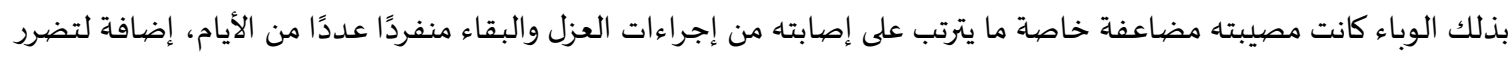

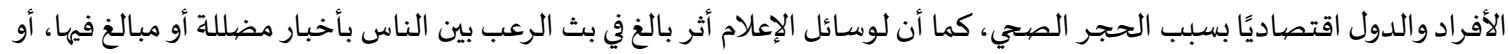

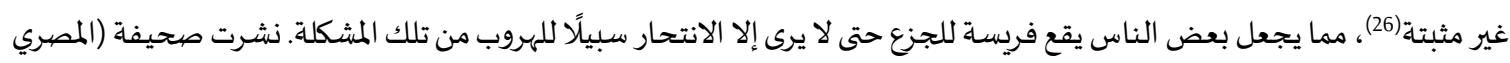

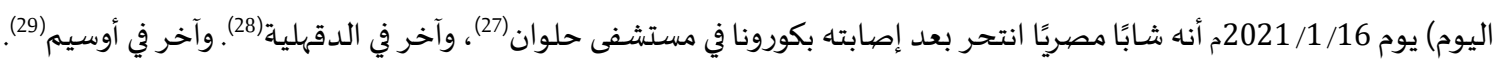

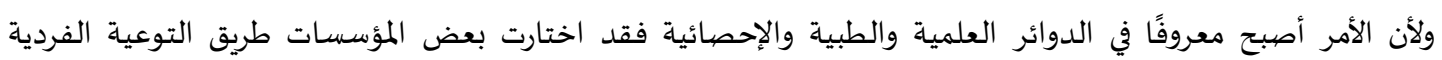

والمجتمعية (30).

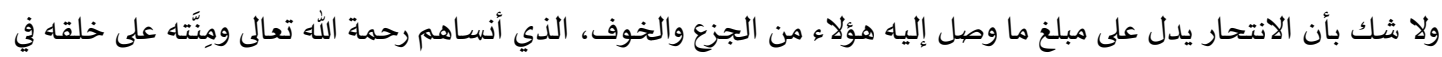

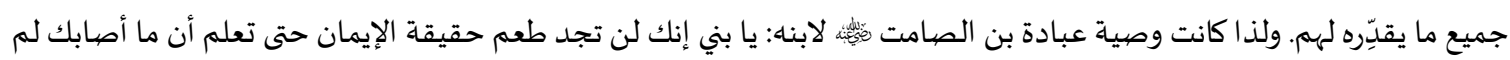

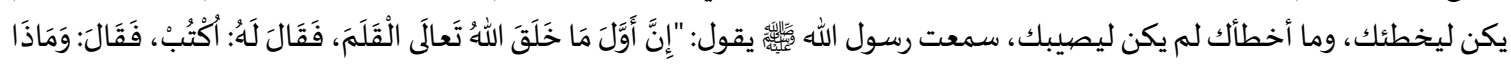

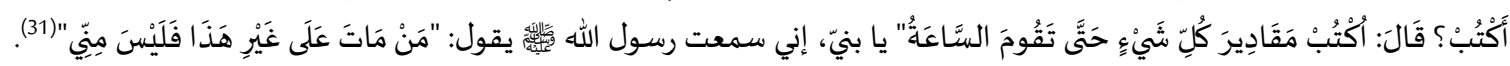

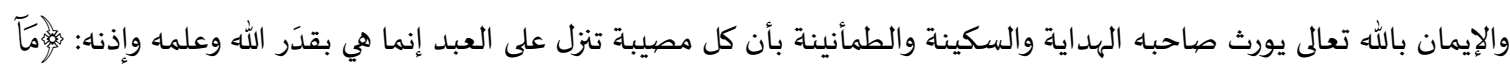

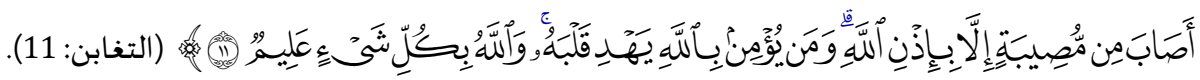

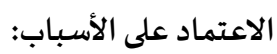

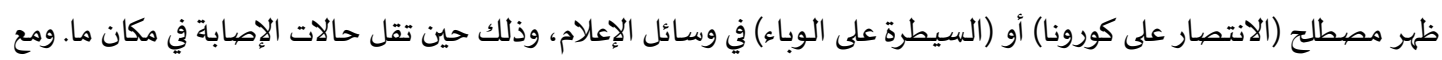

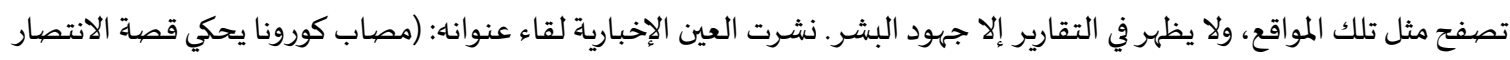

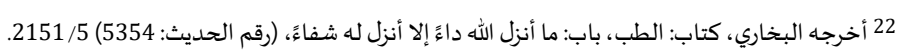

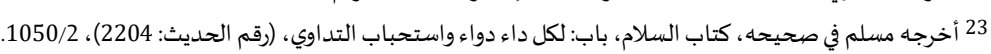

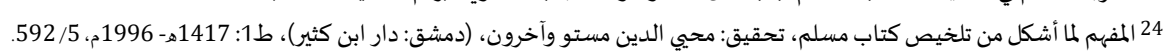

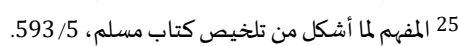

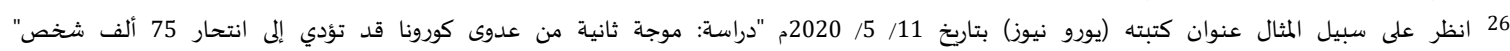
https://arabic.euronews.com/2020/05/11/the-next-covid-crisis-could-be-a-wave-of-suicides https://www.almasryalyoum.com/news/details/2235254 27 https://www.almasryalyoum.com/news/details/22305192021/1/9: 28 2020/6/13 نشر بتاريخ 2020 نشر بتاريخ

https://www.youm7.com/story/2020/6/13/\%D8\%A7\%D9\%86\%D8\%AA\%D8\%AD\%D8\%A7\%D8\%B1\%D8\%B4\%D8\%A7\%D8\%A8-\%D8\%A3\%D8\%B5\%D9\%8A\%D8\%A8-\%D8\%A8\%D8\%A3\%D8\%B2\%D9\%85\%D8\%A9\%D9\%86\%D9\%81\%D8\%B3\%D9\%8A\%D8\%A9-\%D8\%A8\%D8\%B9\%D8\%AF\%D9\%85\%D8\%B9\%D8\%A7\%D9\%86\%D8\%A7\%D8\%AA\%D9\%87-\%D9\%85\%D8\%B9\%D9\%81\%D9\%8A\%D8\%B1\%D9\%88\%D8\%B3-\%D9\%83\%D9\%88\%D8\%B1\%D9\%88\%D9\%86\%D8\%A7/4821917 https:/www.mayoclinic.org/ar/diseases-conditions/coronavirus/in-depth/covid-19- 30 نشر موقع (مايو كلينك) مقالً: كوفيد 19 وخطر الإقبال على الانتحار suicide-risk/art-20490350 31 أخرجه أبو داود في سننه وصححه الألباني، كتاب: السنة، باب في القدر، (رقم الحديث: 4700)، ص850. 


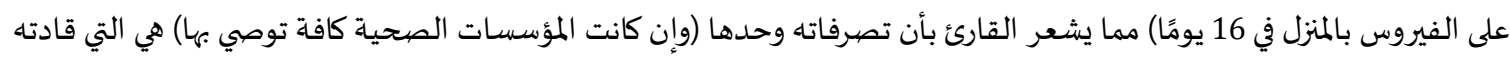

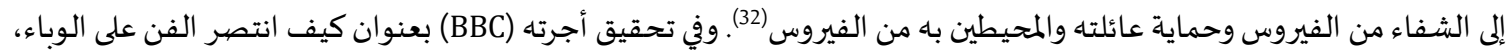

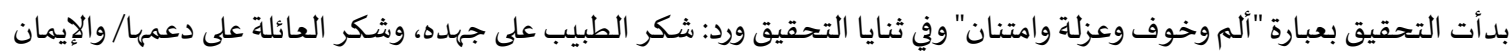

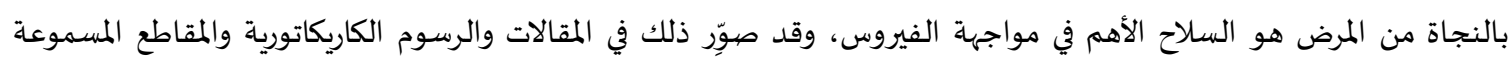

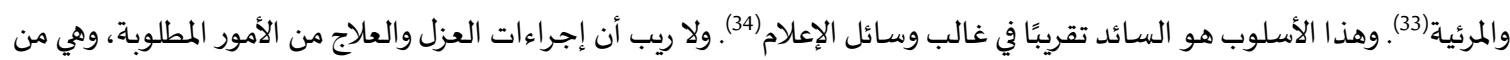

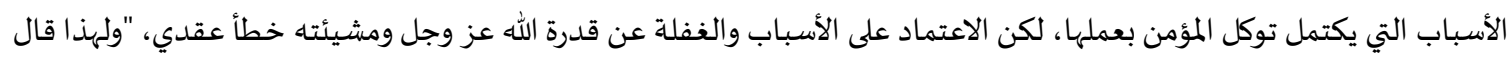

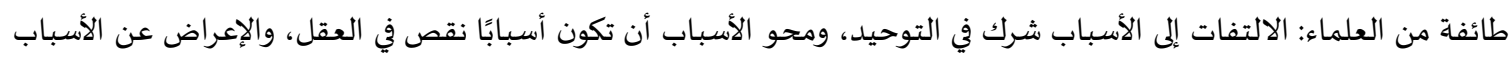

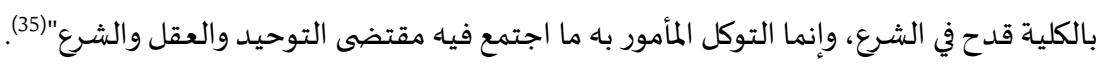

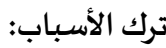

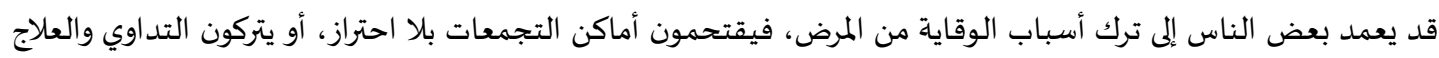

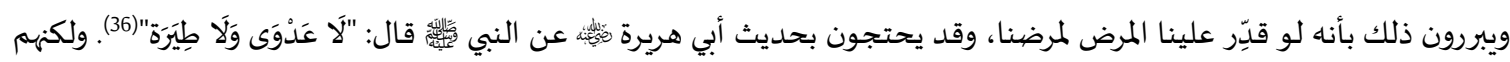

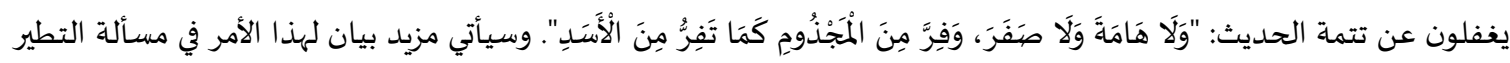

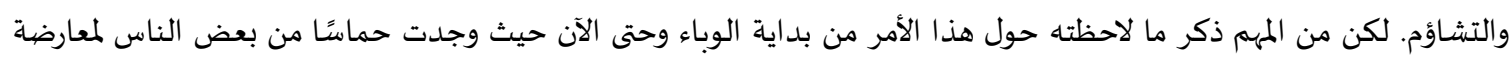

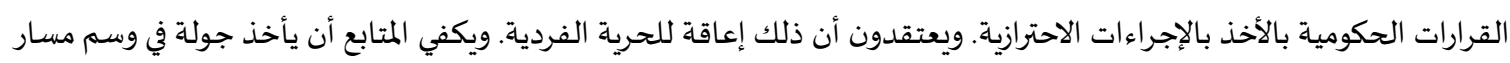

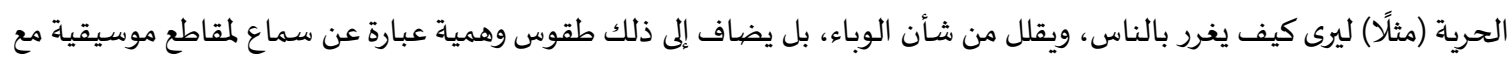

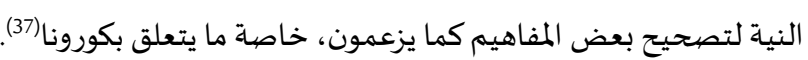

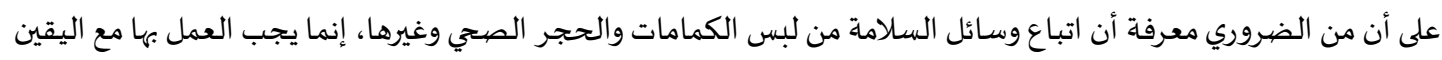

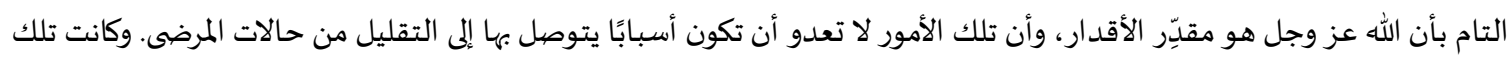

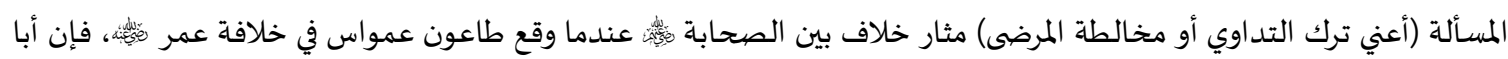

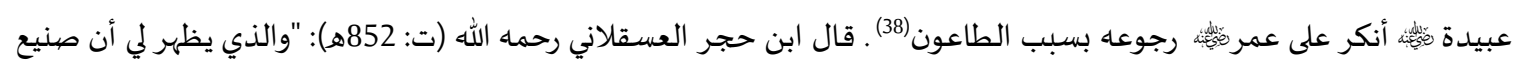

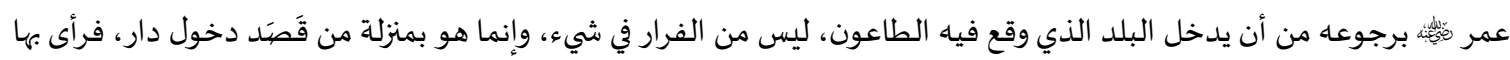

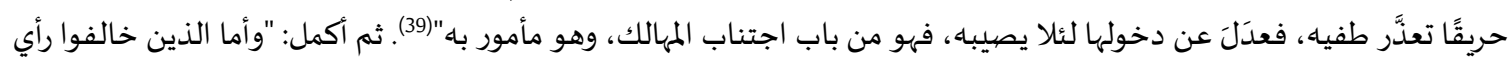

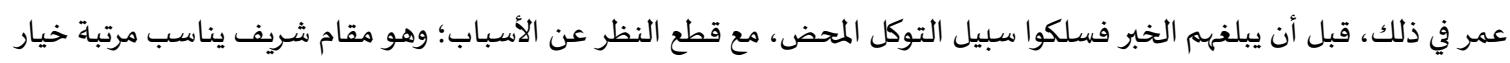

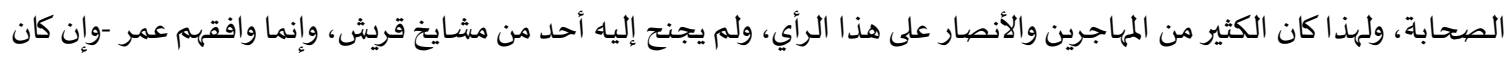

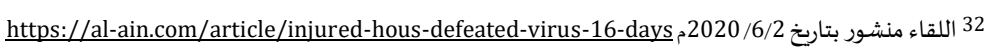
33 نشرت اندبندنت العربية تحقيقًا بتاريخ 2020/7/9م عنونته بـ فنانو الكاريكاتوري العرب يواجهون كورونا بالسخربة والابتسامة ونشرت أول لوحة في التحقيق عبارة عن ممارس

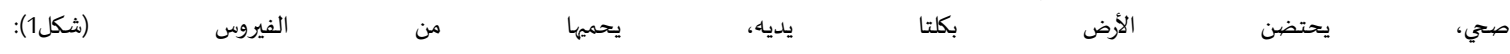
https://www.independentarabia.com/node/133771/\%D8\%AA\%D8\%AD\%D9\%82\%D9\%8A\%D9\%82\%D8\%A7\%D8\%AA\%D9\%88\%D9\%85\%D8\%B7\%D9\%88\%D9\%84\%D8\%A7\%D8\%AA/\%D9\%81\%D9\%86\%D8\%A7\%D9\%86\%D9\%88\%D8\%A7\%D9\%84\%D9\%83\%D8\%A7\%D8\%B1\%D9\%8A\%D9\%83\%D8\%A7\%D8\%AA\%D9\%8A\%D8\%B1\%D8\%A7\%D9\%84\%D8\%B9\%D8\%B1\%D8\%A8-\%D9\%8A\%D9\%88\%D8\%A7\%D8\%AC\%D9\%87\%DD9\%88\%D9\%86\%D8\%A7\%D9\%84\%D8\%B9\%D8\%B1\%D8\%A8-\%D9\%8A\%D9\%88\%D8\%A7\%D8\%AC\%D9\%87\%D9\%88\%D9\%86-
\%D9\%83\%D9\%88\%D8\%B1\%D9\%88\%D9\%86\%D8\%A7-\%D8\%A8\%D8\%A7\%D9\%84\%D8\%B3\%D8\%AE\%D8\%B1\%D9\%8A\%D8\%A9\%D9\%88\%D8\%A7\%D9\%84\%D8\%A7\%D8\%A8\%D8\%AA\%D8\%B3\%D8\%A7\%D9\%85\%D8\%A9 وانظر أيضًا:

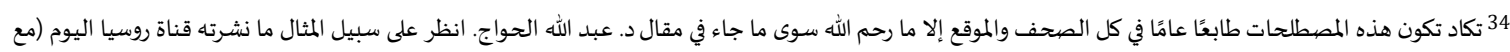

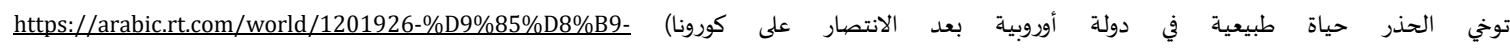
\%D8\%AA\%D9\%88\%D8\%AE\%D9\%8A-\%D8\%A7\%D9\%84\%D8\%AD\%D8\%B0\%D8\%B1-\%D8\%AD\%D9\%8A\%D8\%A7\%D8\%A9\%D8\%B7\%D8\%A8\%D9\%8A\%D8\%B9\%D9\%8A\%D8\%A9-\%D9\%81\%D9\%8A-\%D8\%AF\%D9\%88\%D9\%84\%D8\%A9\%D8\%A3\%D9\%88\%D8\%B1\%D9\%88\%D8\%A8\%D9\%8A\%D8\%A9-\%D8\%A8\%D8\%B9\%D8\%AF\%D8\%A7\%D9\%84\%D8\%A7\%D9\%86\%D8\%AA\%D8\%B5\%D8\%A7\%D8\%B1-\%D8\%B9\%D9\%84\%D9\%89-

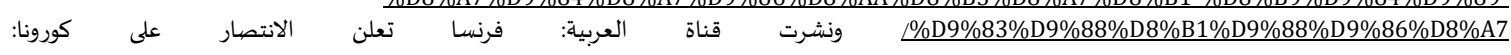

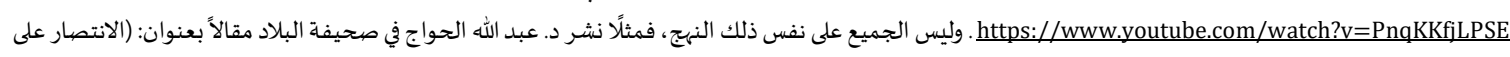

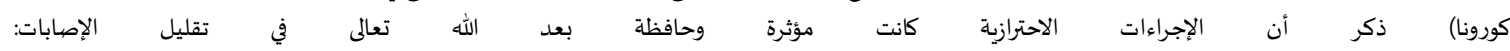
https://www.albiladpress.com/news/2020/4436/columns/683264.html

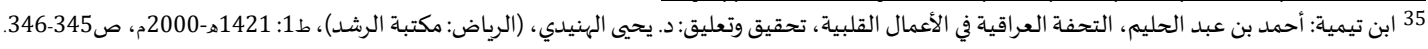
36 أخرجه البخاري في صحيحه، كتاب الطب: باب الجذام، (رقم الحديث:

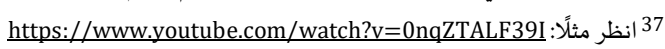

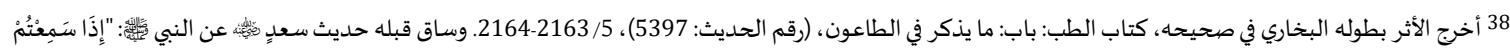

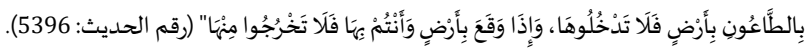

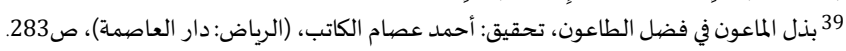

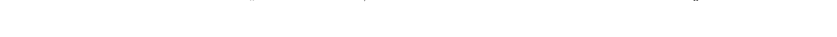


من كبار المهاجرين- لأنه غلب عليه النظر في مصالح المسلمين، وذلك لا يتم إلا بالنظر في الأسباب، والعمل بالراجح منها، مع اعتقاد أن الأمور كلها بتقدير الله" (40).

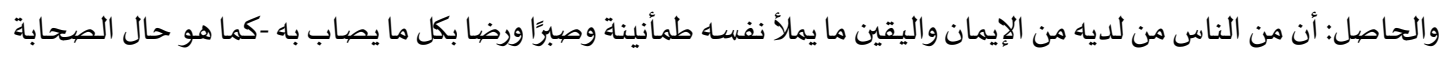

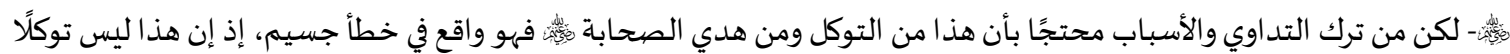

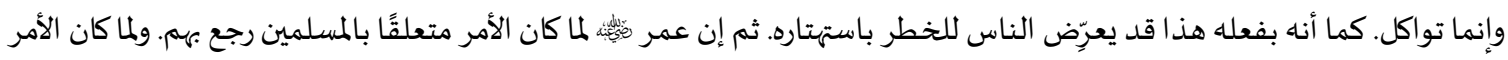

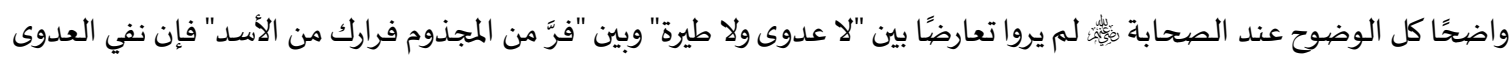

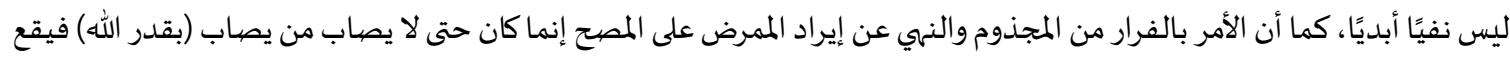

في نفسها أن الأول أعداه

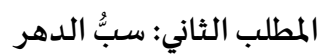

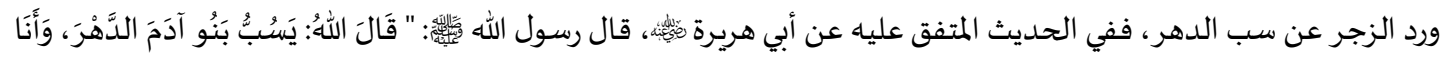

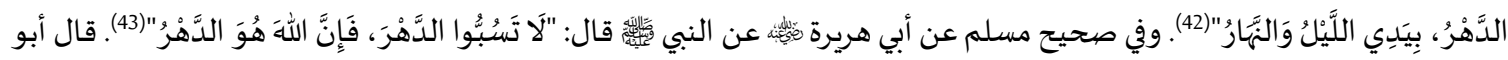

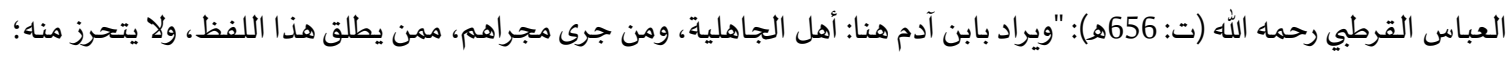

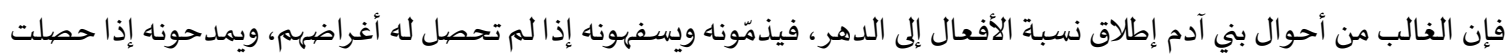

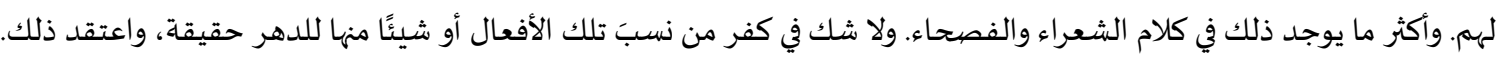

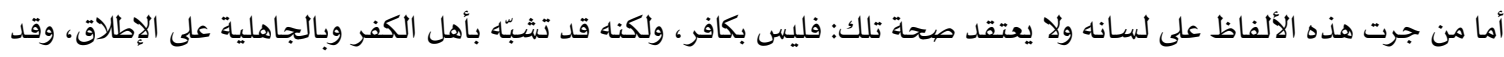

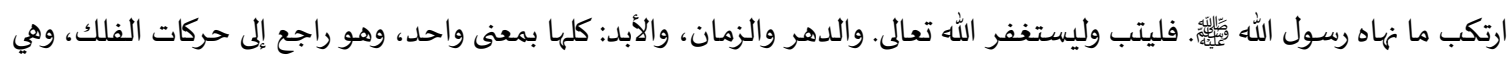
الليل والهار (44).

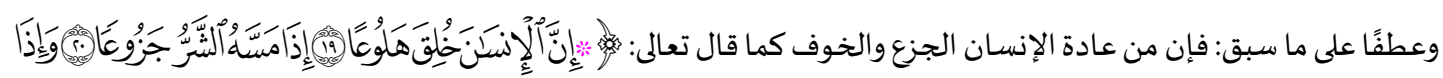

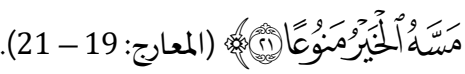

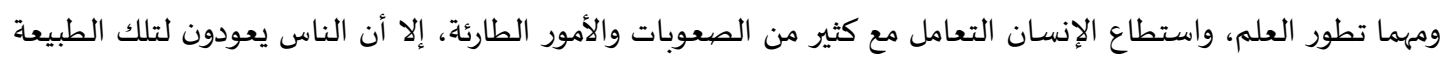

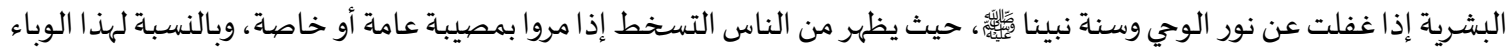

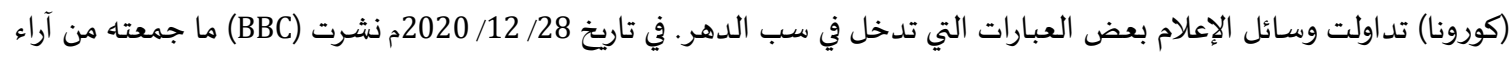

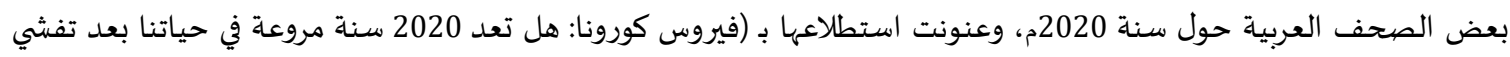

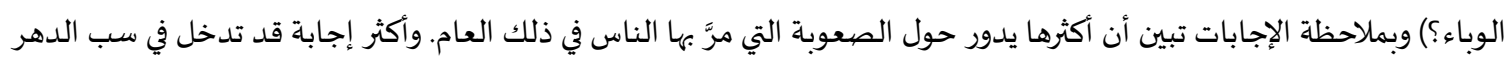

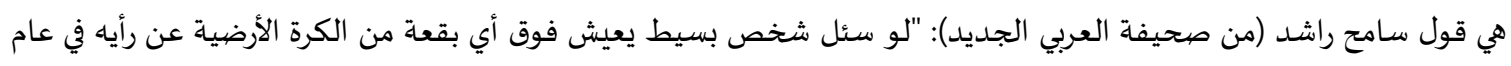

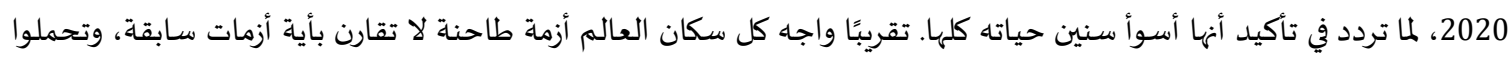
معاناة شديدة لاجتياز هذا العام الثقيل"(45).

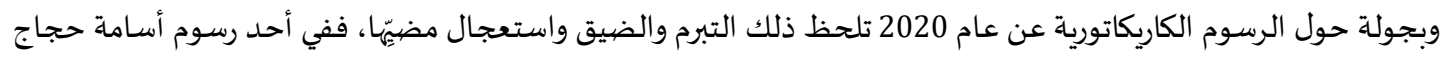

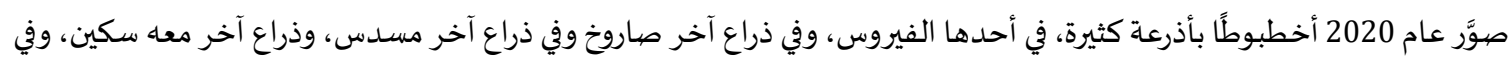

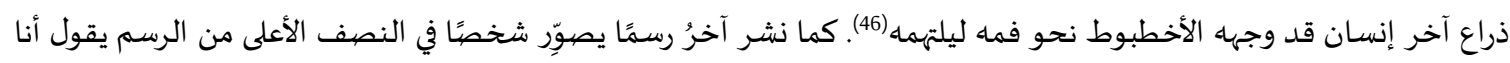

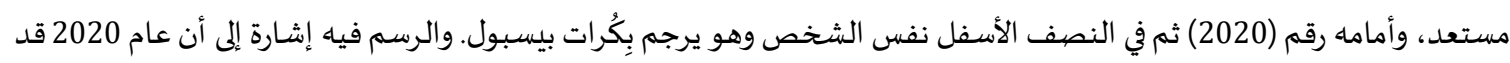

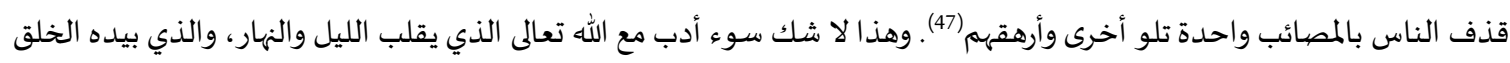

40 بذل الماعون في فضل الطاعون، ص284.

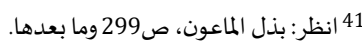

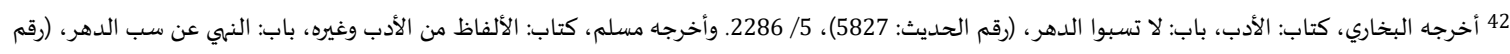

الحديث: 2246)، $1069 / 2$

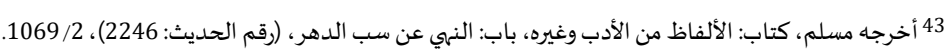

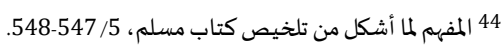

https://www.bbc.com/arabic/inthepress-55466239 45

(شكل2) /https://www.facebook.com/sawaleif/posts/4911501832209478 46

47 https://makkahnewspaper.com/article/1514474/\%D9\%83\%D8\%A7\%D8\%B1\%D9\%8A\%D9\%83\%D8\% A7\%D8\%AA\%D9\%8A\%D8\%B1/\%D9\%83\%D8\%A7\%D8\%B1\%D9\%8A\%D9\%83\%D8\%A7\%D8\%AA\%D9\%8A\%D8\%B1\%D8\%B3\%D9\%86\%D8\%A9-2020 (شكل3) 
والأمر. وفي مقاطع الفيديو، كثير من ذلك التبرم وأشد، بل قد يصل إلى لَعْنُ عام 2020 من قِبَل مشـاهير ومؤثرين في المجتمعات المسلمة وللأسف الشديد. المطلب الثالث: اليأس والقنوط من رحمة الله، والأمن من مكر الله

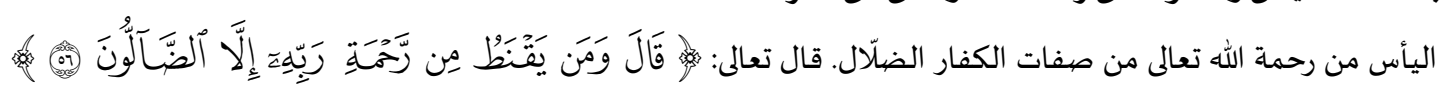

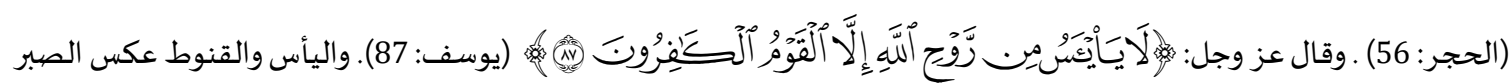
والجَلَد الذي ينبغي أن يتصف بهما المؤمن.

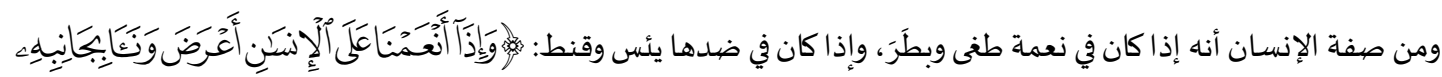

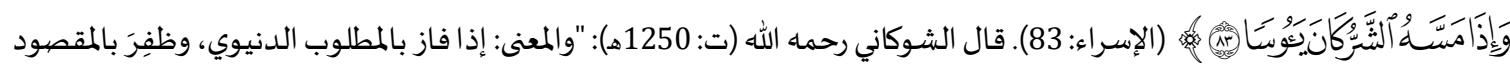
نسي المعبود، وإن فاته شيء من ذلك استولى عليه الأسف، وغلب عليه القنوط، وكلتا الخصلتين قبيحة مذمومة"(48).

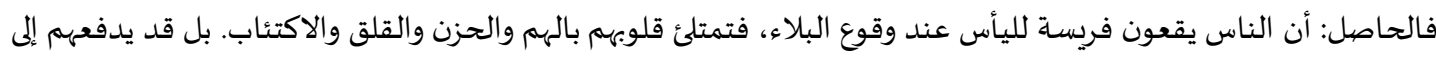

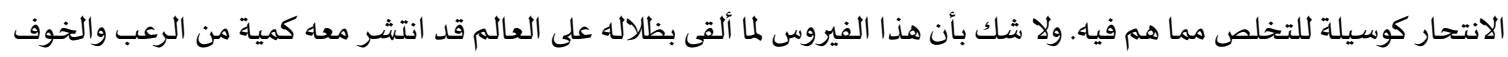
والهلع ساهمت وسائل الإعلام بنشرها بين الناس وللأسف الشديد. وقد مرَّ في المطالب الأولى حديث عن انتحار بعض الشّلى الشباب عند إصابتهم باه. وهذ الا شك من اليأس الذي حرَّمه الله عز وجل، بل هو قادح من قوادح العقيدة، إذ فيه سوء ظن بالله تعالى:

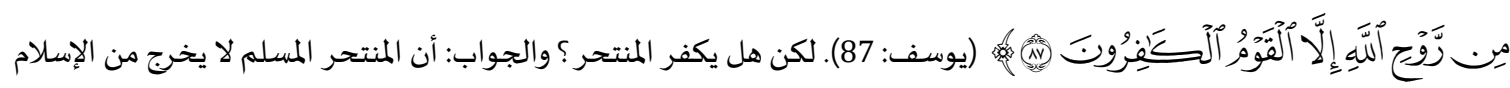
بانتحاره، بل الانتحار معصية وكبيرة من الكبائر، وصاحبها تحت مشيئة الله تعالى، وبهذا كانت ترجمة أحد أبواب كتاب الإيمان في صحيح مسلم: "باب الدليل على أن قاتل نفسـاء لا يكفر "(49).

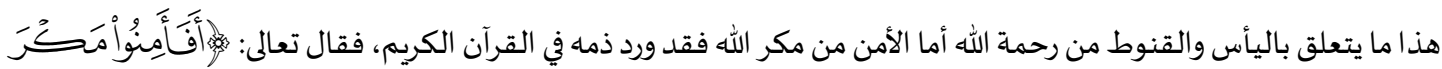

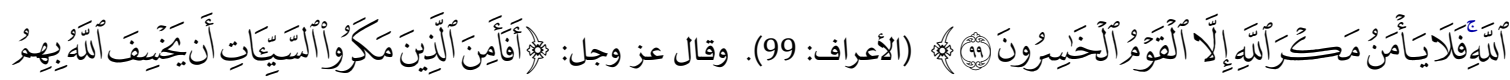

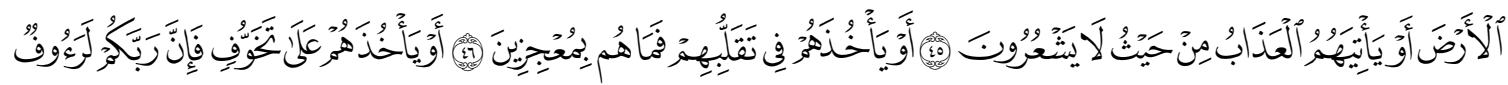

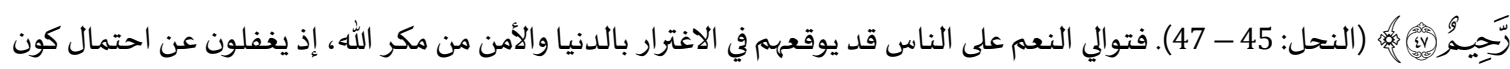

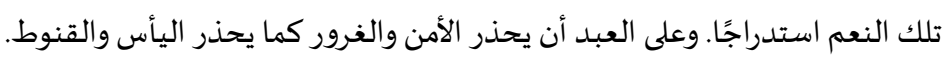

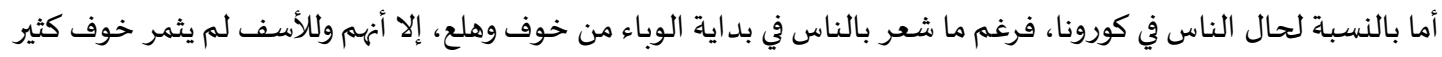

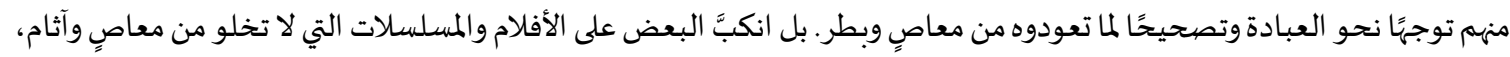

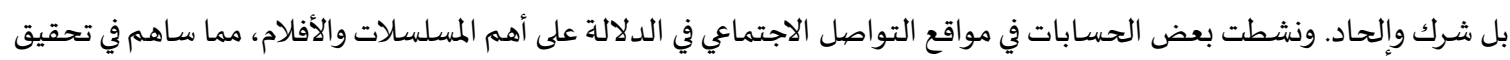

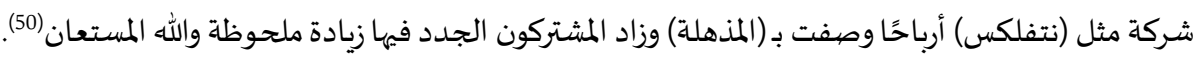

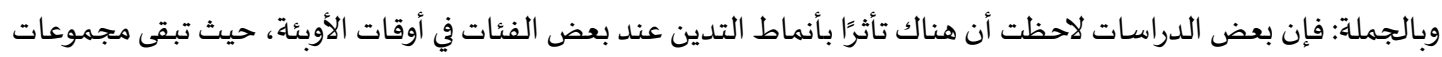

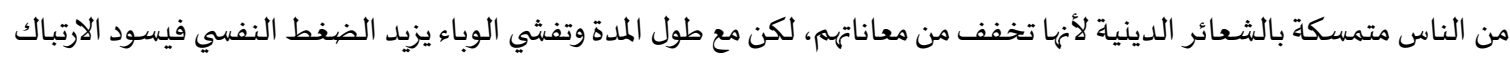

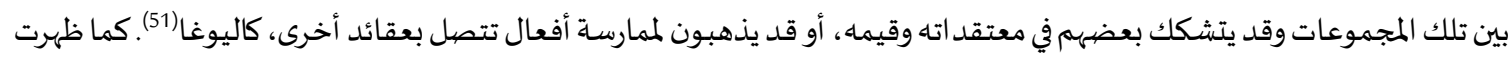
تناقضات بين رغبة بعض الناس في الاحتماء بالدين والقيم، وبين شكوكهم في قدرتها على نجاتهم (52).

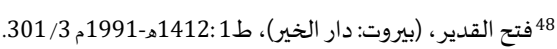

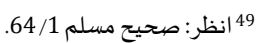

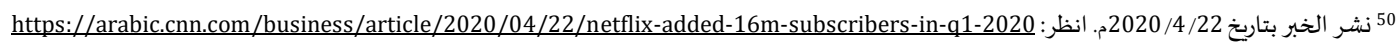

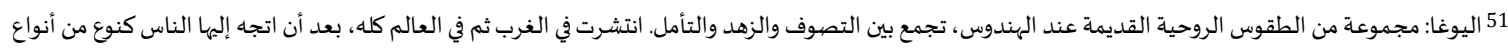

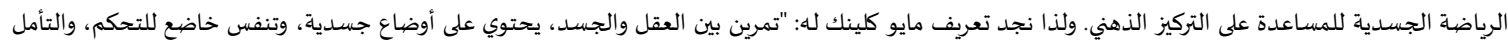

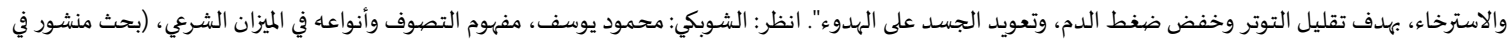

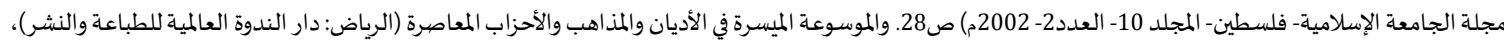

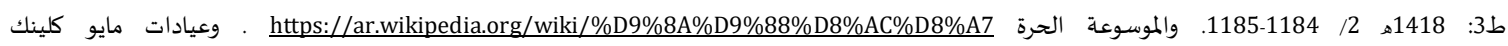
https://www.mayoclinic.org/ar/healthy-lifestyle/stress-management/in-depth/yoga/art-20044733

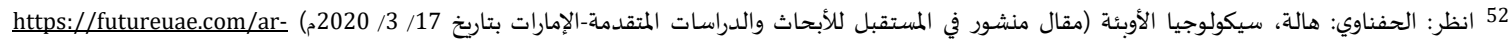

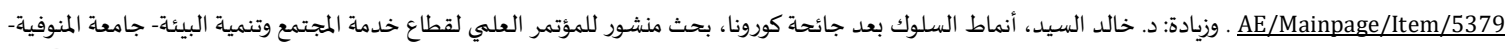


المطلب الر ابع: التطيروالتشاؤم

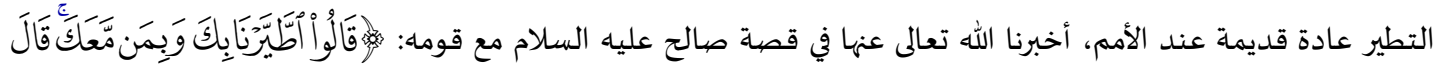

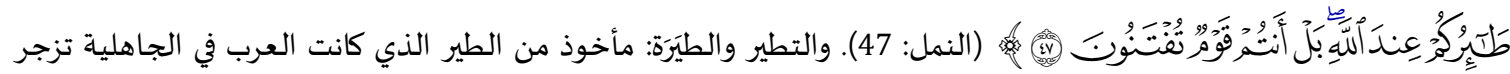

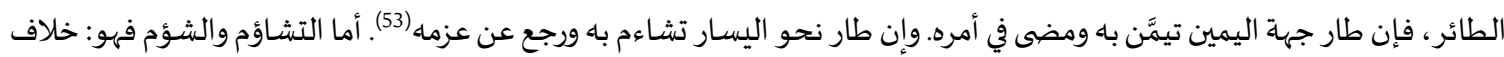

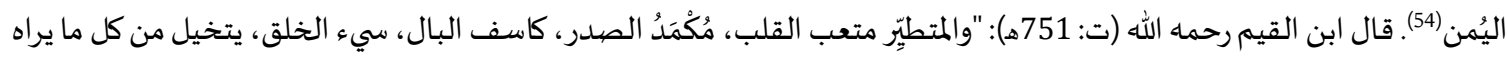

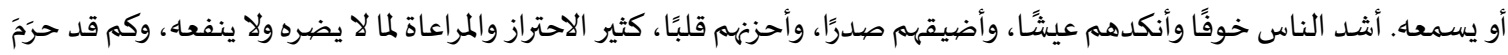
نفسه بذلك من حظ، ومنعها من زرق، وقطع عليها من فائدة" (55).

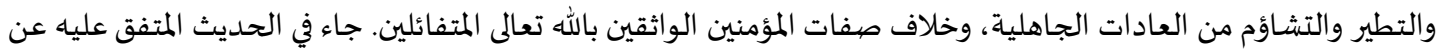

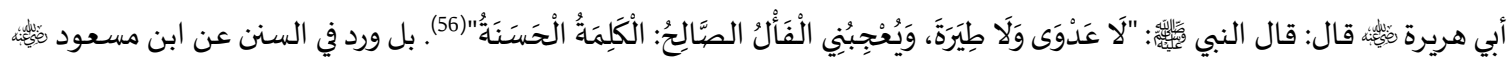

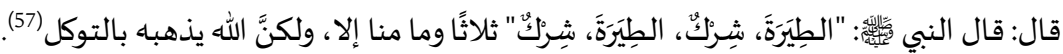

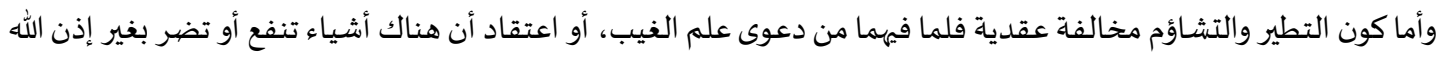

ورغم التقدم العلمي والدعوة إلى ترك الأشياء والمعلومات (غير المثبتة علميًا) إلا أنه ظهر من الناس من يتشاءم من سنة 2020م

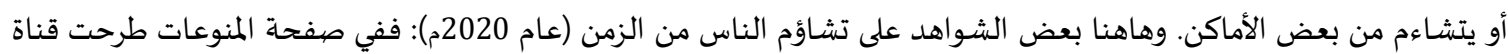

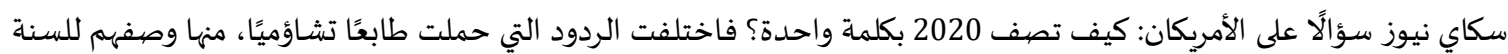

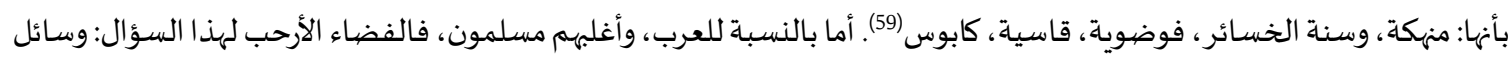

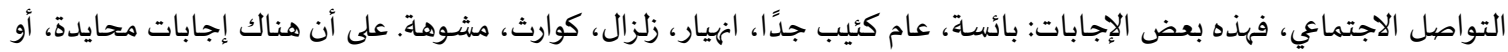

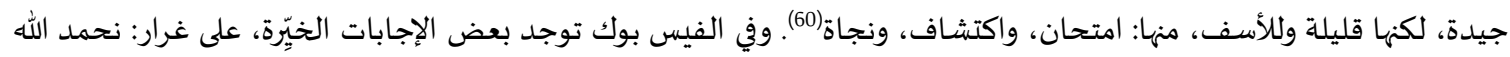

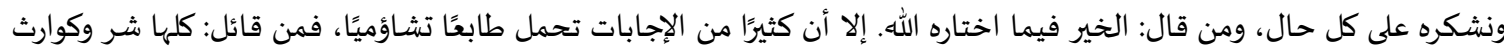

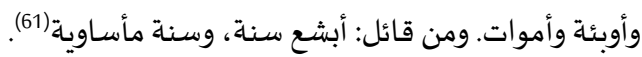

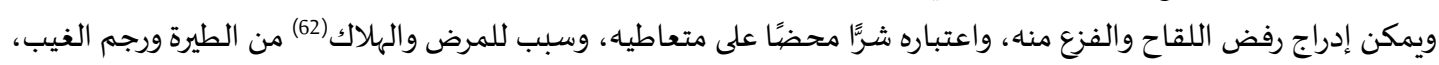

$$
\text { والتشاؤم المنهي عنه. }
$$

ومما سبق يتضيح أنه ما زال كثير من الناس يتشاءم بالأزمان كما يتشاءم بالأمكنة وغيرها. وهذا لا شك من التطير المنهي عنه نهيًا

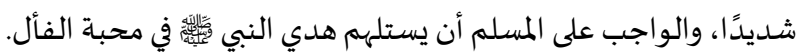
هذا ما تسنى لي جمعه من المخالفات العقدية تختلف بين الكفر والشرك إلى التحريم، ولا يعني القول بالكفر والشرك أنسا أن من وقع

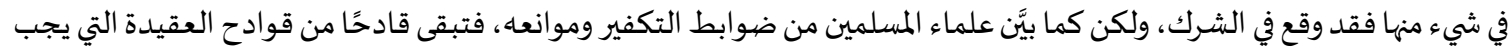

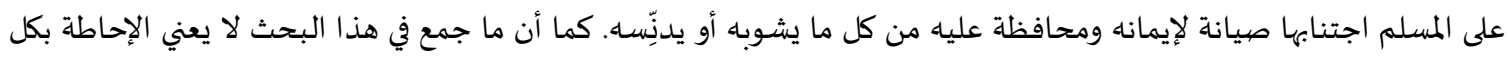

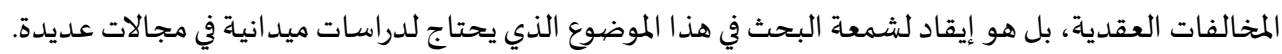

مصر، ص15. ومحمد: م. د. نوفل قحطان وم. م. ياسر محمد حمود، تطبيق تمرينات اليوغا أثناء الحجر المنزلي وتأثيرها على التفكير السلبي والإيجابي لطلاب قسم التربية البدنية

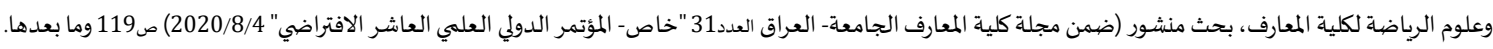

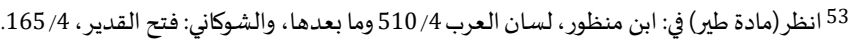

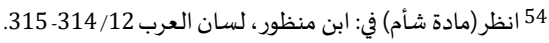

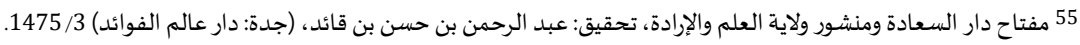

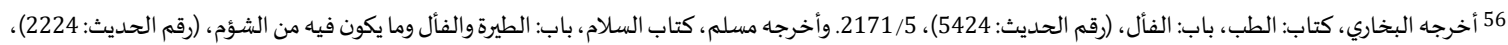

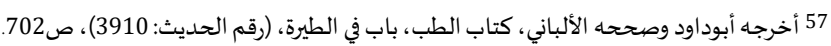

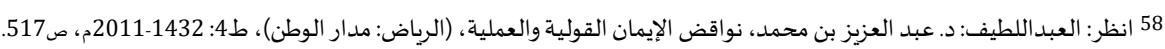
https://www.skynewsarabia.com/varieties/1403557-\%D8\%AA\%D8\%B5\%D9\%81-2020- 59 : \%D8\%A8\%D9\%83\%D9\%84\%D9\%85\%D8\%A9-\%D9\%88\%D8\%A7\%D8\%AD\%D8\%AF\%D8\%A9\%D8\%9F\%D9\%88\%D9\%85\%D8\%A7\%D8\%B0\%D8\%A7-\%D8\%AA\%D8\%AA\%D9\%85\%D9\%86\%D9\%89-2021\%D8\%9F https://www.community.arageek.com/\%d8\%a8\%d9\%83\%d9\%84\%d9\%85\%d8\%a9انظر:

\%d9\%88\%d8\%a7\%d8\%ad\%d8\%af\%d8\%a9\%d8\%8c-\%d8\%b5\%d9\%90\%d9\%81\%d9\%92-2020\%d8\%9f https://m.facebook.com/saasaa2020saasaa/posts/157901529280077 61 62 ظهر في تويتر وسم لا للتطعيم، ولا للتطعيم الإجباري، وكذلك وسم مسار الحرية، كلها تدور حول رفض اللقاح واعتباره سمًا ضارًا بالصحة. ويتناقلون حوادث وفيات يقولون إنها

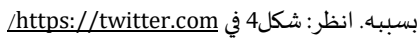


وإن في هذا الوباء لعبرة لمن يعتبر، فرغم التقدم العلمي والطبي والتقني وقف العالم عاجزًا أمام كائن مجهري لا يستطيعون حيلة

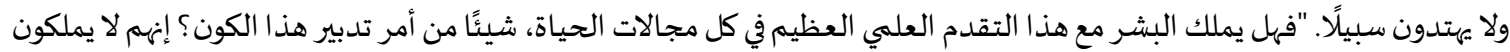

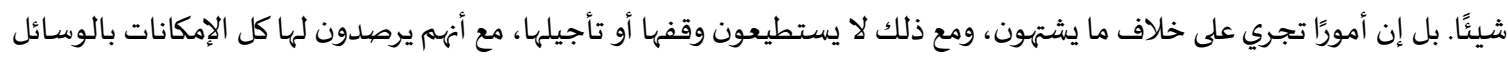

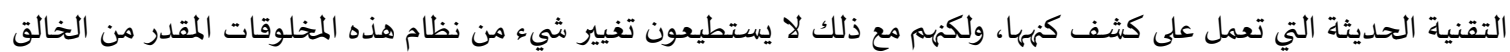

الواحد تعالى"(63).

الخاتمةة:

الحمد لله رب العالمين، والصلاة والسلام على إمام المتوكلين نبينا محمد وعلى آله وصحبه أجمعين، وفي ختام هذه الصفحات يطيب لي ذكر أهم النتائج التي تبيّنت من خلاله: هناك فرق بين الوباء والجائحة، والذي نشرته الجهات الرسمية أن ما يمر به العالم إنما هو جائحة.

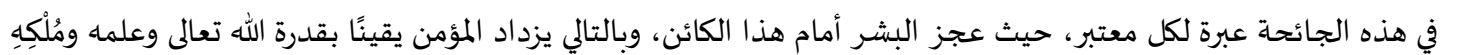
وحكمتاه ورحمته. تنوعت المخالفات العقدية في وباء كورونا بين مخالفات في القدَر (بالجزع وعدم التسليم لأقدار الله تعالى) ومخالفات في التوكل

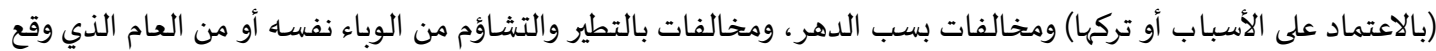
فيه. لم تسلم المجتمعات المسلمة من وجود تلك المخالفات. أكثر المخالفات العقدية الموجودة في المجتمعات المسلمة ناشئة عن الجهل بدين الله إضـافة إلى الخوف والقلق الذي زاد من وتيرته

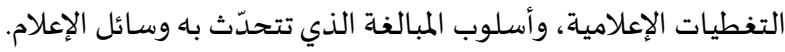
ها لادّعي أني جمعت جميع المخالفات ولا أغلهها، ولكن أهم ما لاحظته في وسائل الإعلام، وما يمكن رصديده وتوثيقهاه خلال تلك الفترة من بداية الوباء وحتى الآن. ولا أنسى أن أقترح تكوين فريق عمل تتضافئ وحتى فياه جهود المخلصين من أهل الاختصاص في الطب والصيدلة والتمريض والأعشاب

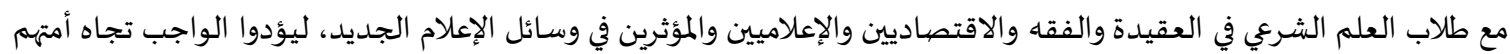
وينيروا الطريق أمامها حتى تمضي تلك المرحلة بأقل قدر من الخسائر، وأكبر قدر من الإسهامات العلمية للأمة المسلمة وللعالم بأسره.

$$
\text { ألمراً: الكتب والأبحاث: }
$$

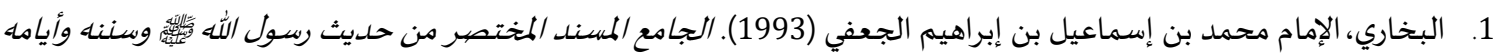

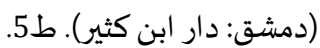

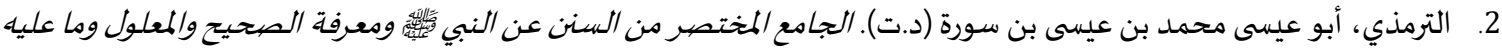

العمل. (عمَّان: بيت الأفكار الدولية).

3. ابن تيمية: أبو العباس أحمد بن عبد الحليم (2000). التحفة العراقية في الأعمال القلبية. تحقيق وتعليق: د. يحيى الهنيدي.

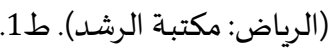

4. ابن تيمية: أبو العباس أحمد بن عبد الحليم (1991). مجموع الفتاوى. جمع وترتيب: عبد الرحمن بن قاسم العاصمي. (الرياض: دار عالم الكتب).

5. ابن جرير الطبري. أبو جعفر محمد بن جرير بن يزيد. (2000). جامع البيان في تأويل آي القرآن. تحقيق: أحمد ومحمود شاكر.

(بيروت: مؤسسة الرسالة). طان.

6. ابن حجر العسقلاني، أحمد بن علي. (د.ت). بذل الماعون في فضيل الطاعون. تحقيق: أحمد عصيام الكاتب. (الرياض: دار العاصيمة). 7. الحفناوي، هالة (2020). سيكولوجيا الأوبئةً. (مقال منشور في المستقبل للأبحاث والدراسات المتقدمة-الإمارات).

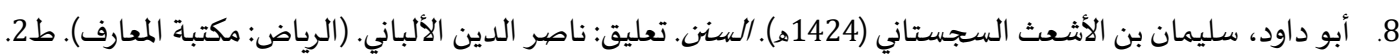
9. زيادة، خالد السي. أنماط السلوك بعدل جائحة كورونا. بحث منشور للمؤتمر العلمي لقطاع خدمة المجتمع وتنمية البيئة- جامعاة 
10. السعدي، عبد الرحمن بن ناصر (2000). تيسير الككريم الرحمن في تفسير كلام المنان. تحقيق: د. عبد الرحمن بن معلا اللويحق.

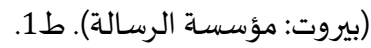

11. الشوبكي، محمود يوسف (2002). مفهوم التصوف وأنواعه في الميزان الشـرعي. مجلة الجامعة الإسلامية: 12(2).

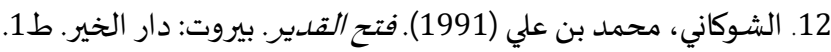

13. العبد اللطيف، عبد العزيز بن محمد (2011). نواقض الإيمان القولية والعملية. الرياض: مدار الوطن. ط4.

14. ابن فارس، أبو الحسين أحمد. (1994). المقايسيس في اللغة. تحقيق: شهاب الدين أبو عمرو. (بيروت: دار الفكر). طان. 15. القرطبي، أبو العباس أحمد بن عمر بن إبراهيم (1996). المفهم لما أشكل من تلخيص كتاب مسلم. تحقيق وتعليق: محيي الدين

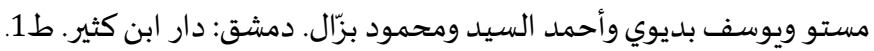

16. ابن قيم الجوزية، شمس الدين محمد بن أبي بكر الزرعي (1433ه). الطب النبوي. (جدة: دار السلام للنشر والتوزيح). 17. ابن قيم الجوزية، شمس الدين محمد بن أبي بكر الزرعي (د.ت). إغاثة اللهفان من مصائد الشيطان. تحقيق: محمد عزيز شمس. جدة: دار عالم الفوائد.

18. ابن قيم الجوزية، شمس الدين محمد بن أبي بكر الزرعي. مفتاح دار السعادة ومنشور ولاية العلم والإرادة. تحقيق: عبد الرحمن بن

$$
\text { حسن بن قائد. جدة: دار عالم الفوائد. }
$$

19. ابن ماجها، أبو عبد الله محمد بن يزيد القزويني. تحقيق: محمد فؤاد عبد الباقي. (دمشق: دار إحياء الكتب العربية). بدون تاريخ نشر.

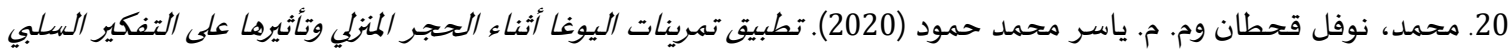
والإيجابي لطالاب قسم التربية البدنية وعلوم الرياضية لكلية المعارف. بحث منشور (ضمن مجلة كلية المعارف الجامعة- العراق

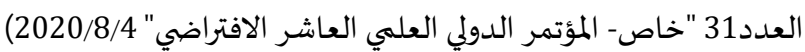

21. المحمود، عبد الرحمن بن صالح (2011).تيسير لمعة الاعتقاد للإمام /بن قدامة المقلسي. الرياض: مدار الوطن للنشر. ط2.

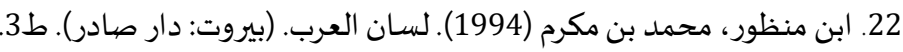

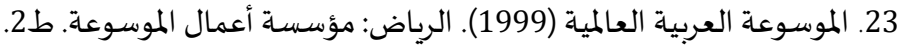

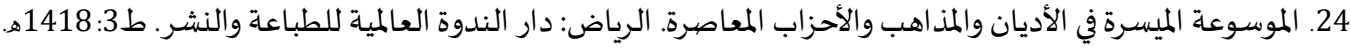

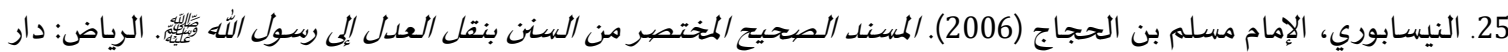
https://www.moh.gov.sa 1 موقع وزارة الصحة السعودية

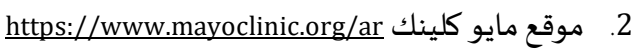
https://ar.wikipedia.org 3. https://makkahnewspaper.com صحيفة مكة https://www.albiladpress.coml 5 صحيفة البلاد

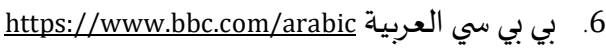
https://www.independentarabia.com اندبندنت

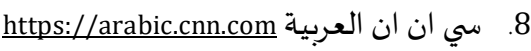

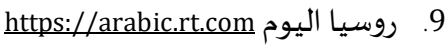

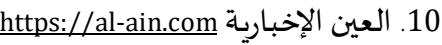

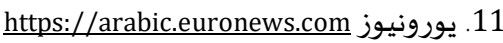
12. 12 اليوم السابع 13ttps:/www.youm7.com https://www.almasryalyoum.com 13. المصري اليوم اسعايع 11. https://www.skynewsarabia.com 14. سكاي نيوز https://facebook.com 15 فيس بوك نوك 16. بويتر Lhttps://twitter.com

17 17 يوتيوب 18 https://www.community.arageek.com .18 


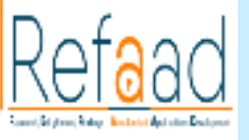

www.refaad.com
المجلة الدولية للدراسـات الإسلامية المتخصصية

International Journal of Specialized Islamic Studies (SIS) Journal Homepage: https://www.refaad.com/views/SIS/Home.aspx ISSN: 2617-6246(Online) 2617-6238(Print)

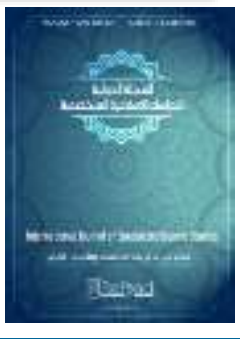

\section{The Infractions of Belief in the Time of Epidemics (Corona Model)}

\section{Wafa Alkhamees}

King Saud University, KSA

walkhamees@ksu.edu.sa

DOI: https://doi.org/10.31559/SIS2020.5.2.3

Abstract: This research adopts a descriptive and analytical approach.

The epidemic has swept the world over the past two years. Which shut down many people's activities. It is important to study this matter and its impact on the people. Some Infractions affecting the Muslim's belief and faith. Therefore, I choose study these Infractions in a scientific.

Particpation in the special edition of the International Journal of Specialized Islamic Studies.

The Study objectives: Knowing the difference between disease, epidemic and pandemic, introducing a legitimate approach to dealing with epidemics, Statement the Infractions of belief which people fall during the time of epidemics, highlighting what people should be doing at the time of pandemics.

Keywords: Infraction; Belief; Faith; Destiny; Confidence; Pessimism; Despair; Diseases; Epidemics; Corona.

\section{References:}

1. Al'bdalltyf, 'bd Al'zyz Bn Mhmd (2011). Nwaqd Aleyman Alqwlyh Wal'mlyh. Alryad: Mdar Alwtn. T4.

2. Abn Fars, Abw Alhsyn Ahmd. (1994). Almqayys Fy Allghh. Thqyq: Shhab Aldyn Abw 'mrw. (Byrwt: Dar Alfkr). T1.

3. Abn Hjr Al'sqlany, Ahmd Bn 'ly. (D.T). Bdl Alma'wn Fy Fdl Alta'wn. Thqyq: Ahmd 'sam Alkatb. (Alryad: Dar Al'asmh).

4. Abn Jryr Altbry. Abw J'fr Mhmd Bn Jryr Bn Yzyd. (2000). Jam' Albyan Fy Tawyl Ay Alqran. Thqyq: Ahmd Wmhmwd Shakr. (Byrwt: M'sst Alrsalh). T1.

5. Abn Majh, Abw 'bd Allh Mhmd Bn Yzyd Alqzwyny. Thqyq: Mhmd F'ad 'bd Albaqy. (Dmshq: Dar Ehya' Alktb Al'rbyh). Bdwn Tarykh Nshr.

6. Abn Mnzwr, Mhmd Bn Mkrm (1994). Lsan Al'rb. (Byrwt: Dar Sadr). T3.

7. Abn Qym Aljwzyh, Shms Aldyn Mhmd Bn Aby Bkr Alzr'y (1433h). Altb Alnbwy. (Jdh: Dar Alslam Llnshr Waltwzy').

8. Abn Qym Aljwzyh, Shms Aldyn Mhmd Bn Aby Bkr Alzr'y (D.T). Eghathh Allhfan Mn Msa'd Alshytan. Thqyq: Mhmd 'zyz Shms. Jdh: Dar 'alm Alfwa'd.

9. Abn Qym Aljwzyh, Shms Aldyn Mhmd Bn Aby Bkr Alzr'y. Mftah Dar Als'adh Wmnshwr Wlayh Al'lm Waleradh. Thqyq: 'bd Alrhmn Bn Hsn Bn Qa'd. Jdh: Dar 'alm Alfwa'd.

10. Abn Tymyh: Abw Al'bas Ahmd Bn 'bd Alhlym (2000). Althfh Al'raqyh Fy Ala'mal Alqlbyh. Thqyq Wt'lyq: D. Yhya Alhnydy. (Alryad: Mktbt Alrshd). T1.

11. Abn Tymyh: Abw Al'bas Ahmd Bn 'bd Alhlym (1991). Mjmw' Alftawa. Jm' Wtrtyb: 'bd Alrhmn Bn Qasm Al'asmy. (Alryad: Dar 'Ealm Alktb).

12. Abw Dawd, Slyman Bn Alash'th Alsjstany (1424h). Alsnn. T'lyq: Nasr Aldyn Alalbany. (Alryad: Mktbt Alm'arf). T2. 
13. Albkhary,Alemam Mhmd Bn Esma'yl Bn Ebrahym Alj'fy (1993). Aljam' Almsnd Almkhtsr Mn Hdyth Rswl Allh Whnn Wayamh. (Dmshq: Dar Abn Kthyr). T5.

14. Alhfnawy, Halh (2020). Sykwlwjya Alawb'h. (Mqal Mnshwr Fy Almstqbl Llabhath Waldrasat AlmtqdmhAlemarat).

15. Mhmd, Nwfl Qhtan Wm. M. Yasr Mhmd Hmwd (2020). Ttbyq Tmrynat Alywgha Athna' Alhjr Almnzly Wtathyrha 'la Altfkyr Alslby Waleyjaby Ltlab Qsm Altrbyh Albdnyh W'lwm Alryadh Lklyt Alm'arf. Bhth Mnshwr (Dmn Mjlt Klyt Alm'arf Aljam'h- Al'raq Al'edd31 "Khas- Alm'tmr Aldwly Al'lmy Al'ashr Alaftrady" $4 / 8 / 2020)$

16. Almhmwd, 'bd Alrhmn Bn Salh (2011). Tysyr Lm'h Ala'tqad Llemam Abn Qdamh Almqdsy. Alryad: Mdar Alwtn Llnshr. T2.

17. Almwsw'h Al'rbyh Al'almyh (1999). Alryad: M'sst A'mal Almwsw'h. T2.

18. Almwsw'h Almysrh Fy Aladyan Walmdahb Walahzab Alm'asrh. Alryad: Dar Alndwh Al'almyh Lltba'h Walnshr. T3: 1418h.

19. Alnysabwry, Alemam Mslm Bn Alhjaj (2006). Almsnd Alshyh Almkhtsr Mn Alsnn Bnql Al'dl Ela Rswl Allh 締. Alryad: Dar Tybh. T1.

20. Alqrtby, Abw Al'bas Ahmd Bn 'mr Bn Ebrahym (1996). Almfhm Lma Ashkl Mn Tlkhys Ktab Mslm. Thqyq Wt'lyq: Mhyy Aldyn Mstw Wywsf Bdywy Wahmd Alsyd Wmhmwd Bzal. Dmshq: Dar Abn Kthyr. T1.

21. Als'dy, 'bd Alrhmn Bn Nasr (2000). Tysyr Alkrym Alrhmn Fy Tfsyr Klam Almnan. Thqyq: D. 'bd Alrhmn Bn M'la Allwyhq. (Byrwt: M'sst Alrsalh). T1.

22. Alshwbky, Mhmwd Ywsf (2002). Mfhwm Altswf Wanwa'h Fy Almyzan Alshr'y. Mjlt Aljam'h Aleslamyh: $10(2)$.

23. Alshwkany, Mhmd Bn 'ly (1991). Fth Alqdyr. Byrwt: Dar Alkhyr. T1.

24. Altrmdy, Abw 'ysa Mhmd Bn 'ysa Bn Swrh (D.T). Aljam' Almkhtsr Mn Alsnn 'n Alnby 綖 Wm'rfh Alshyh Walm'lwl Wma 'lyh Al'ml. ('mán: Byt Alafkar Aldwlyh).

25. Zyadh, Khald Alsy. Anmat Alslwk B'd Ja'hh Kwrwna. Bhth Mnshwr Llm'tmr Al'lmy Lqta' Khdmt Almjtm' Wtnmyh Alby'h- Jam't Almnwfyh- Msr 
شكل (1)

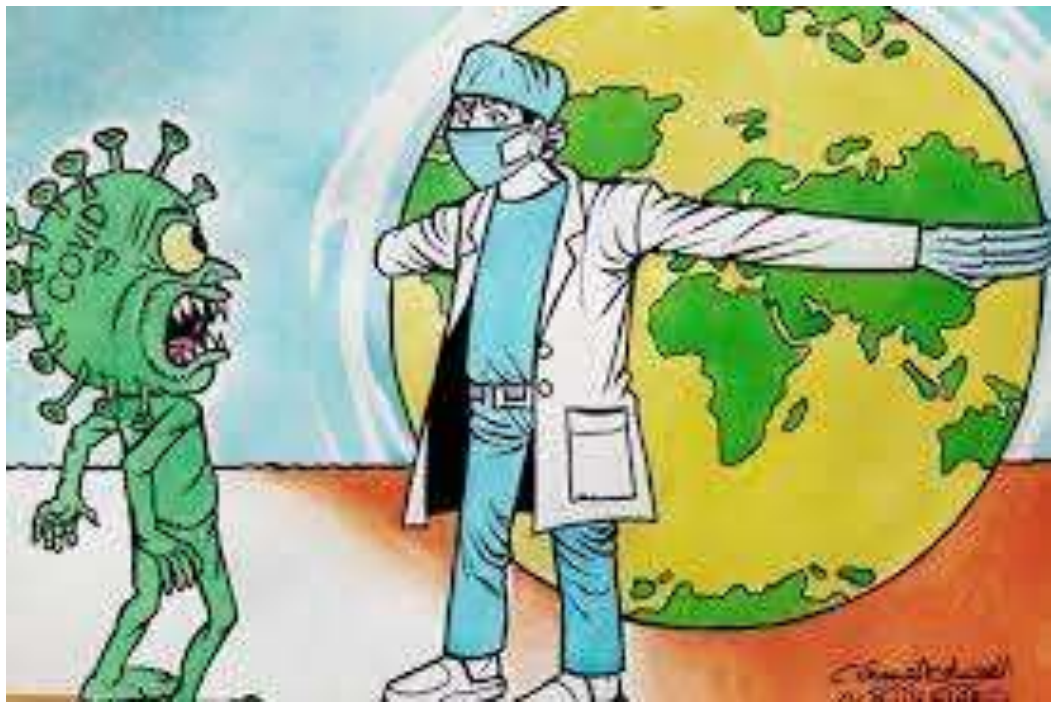

شكل 2

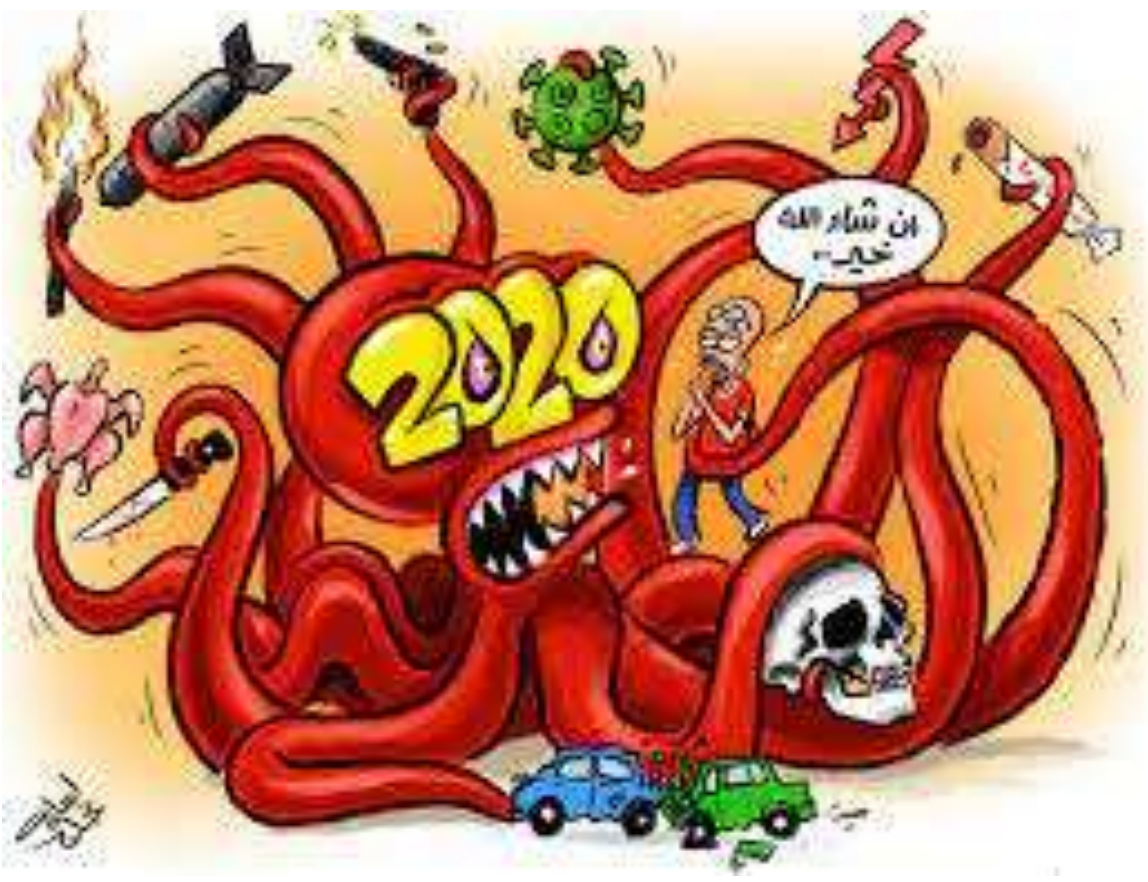




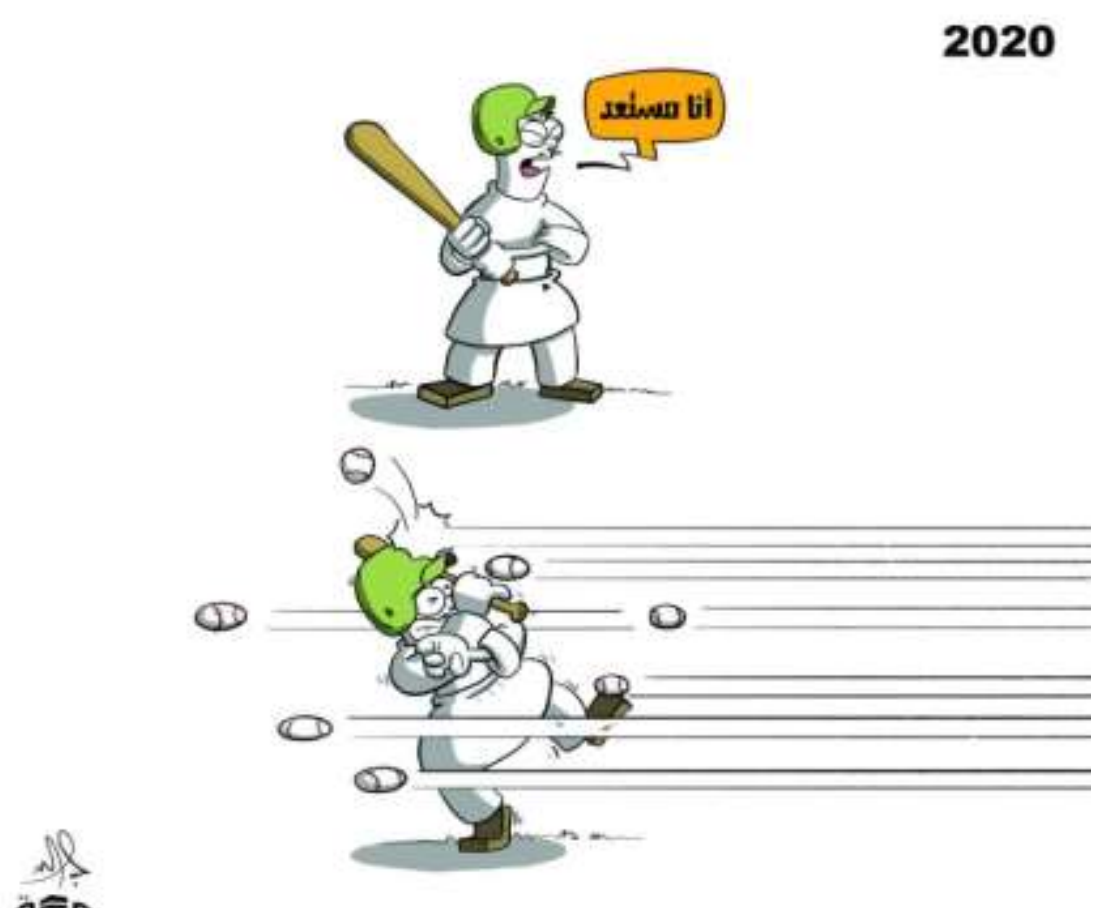

مكة

شكل 4

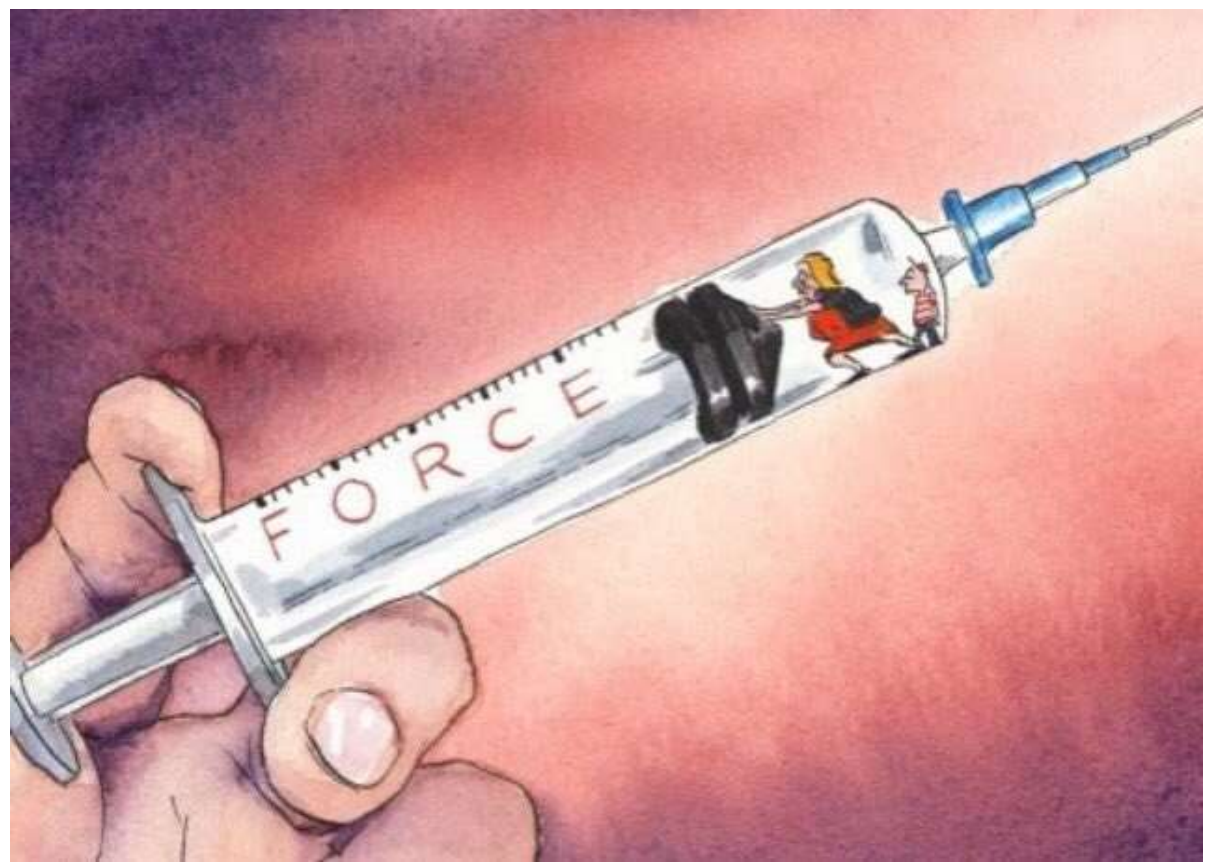

